Proposta de arquitetura para federações de nuvens computacionais acadêmicas

\author{
Gabriel Araujo von Winckler
}

DisSERTAÇÃO APRESENTADA

AO

Instituto DE MATEMÁticA E EstatísticA

DA

Universidade DE SÃo PAUlo

PARA

OBTENÇÃO DO TÍTULO

$\mathrm{DE}$

Mestre em CiÊNCIAS

Programa: Ciência da Computação

Orientador: Marco Dimas Gubitoso

São Paulo, Agosto de 2014 


\section{Proposta de arquitetura para federações de nuvens computacionais acadêmicas}

Esta versão da dissertação contém as correções e alterações sugeridas pela Comissão Julgadora durante a defesa da versão original do trabalho, realizada em 22/10/2014. Uma cópia da versão original está disponível no

Instituto de Matemática e Estatística da Universidade de São Paulo.

Comissão Julgadora:

- Prof. Dr. Marco Dimas Gubitoso (orientador) - IME-USP

- Prof. Dr. Daniel de Angelis Cordeiro - IME-USP

- Prof ${ }^{a}$. Dra ${ }^{a}$ Liria Matsumoto Sato - EP-USP 


\section{Agradecimentos}

Gostaria de agradecer o apoio recebido por diversos professores do departamento de computação da USP, em especial ao meu orientador, Gubi. Por chegar com uma formação bastante distinta, tinha receio de encontrar grandes dificuldade. Só encontrei apoio e grandes lições.

Agradeço também ao Sérgio Novaes, que além de chefe, é uma importante referência na minha vida profissional. Obrigado por todas as oportunidades.

Por fim, nada disso teria valor se não pela minha família e meus amigos. Sou especialmente grato à minha esposa, Stef. Obrigado pelo carinho, apoio e paciência.

Esta pesquisa tornou-se possível graças aos recursos computacionais disponibilizados pelo Núcleo de Computação Científica (NCC/GridUnesp) da Universidade Estadual Paulista (UNESP). 


\section{Resumo}

von Winckler, G. A. Proposta de arquitetura para federações de nuvens computacionais acadêmicas. 2014. 53 f. Dissertação (Mestrado) - Instituto de Matemática e Estatística, Universidade de São Paulo, São Paulo, 2014.

A computação em nuvem tem recebido um grande destaque, ao propor um novo e eficiente mecanismo para disponibilizar recursos computacionais. Dos investimentos cada vez maiores nessa plataforma, inclusive pela academia, surge a oportunidade de compartilhar estes recursos computacionais entre diferentes instituições. As grades computacionais são um mecanismo bem estabelecido para o compartilhamento de alguns tipos de recursos computacionais. Através do entendimento de como isso é feito nestas estruturas, esse trabalho avalia as soluções existentes e propõe um arquitetura alternativa que permite a criação das federações de nuvens computacionais.

Palavras-chave: nuvens computacionais, grades computacionais, eScience, computação científica, federação. 


\section{Abstract}

von Winckler, G. A. Design proposal for academic cloud computing federations. 2014. 53

f. Dissertação (Mestrado) - Instituto de Matemática e Estatística, Universidade de São Paulo, São Paulo, 2010.

Cloud computing is a new model to provide computing resources. The growing interest and investments on this platform creates an opportunity to share this resources across different institutions. The grid computing is the standard way of achieving this. Using grid as reference, this work survey current technologies and present an alternative design to allow the development of academic cloud computing federations.

Keywords: cloud computing, grid computing, eScience, scientific computing, federation. 


\section{Sumário}

Lista de Abreviaturas $\quad$ vi

Lista de Figuras $\quad$ viii

1 Introdução $\quad 1$

1.1 Motivação . . . . . . . . . . . . . . . . . . . . . . . . . . . 1

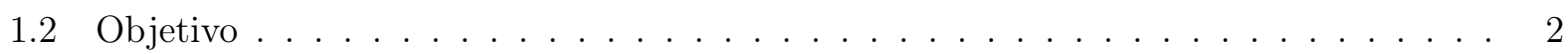

1.3 Metodologia . . . . . . . . . . . . . . . . . . . 3

1.4 Organização . . . . . . . . . . . . . . . . . . . . . . . . . 3

2 Conceitos $\quad 4$

2.1 Federações de recursos computacionais . . . . . . . . . . . . . . . . . . . . . 4

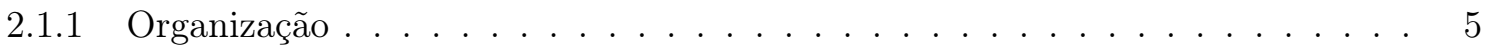

2.2 Grades computacionais . . . . . . . . . . . . . . . . . . . . . 5

2.2 .1 Globus Toolkit . . . . . . . . . . . . . . . . . . . 6

2.2 .2 Gerenciamento de execução . . . . . . . . . . . . . . . . . . . . . . . 7

2.2 .3 Armazenamento de dado . . . . . . . . . . . . . . . . . . 8

2.2 .4 Autenticação e autorização . . . . . . . . . . . . . . . . . . . . . . 9

2.2.5 Registro e descoberta . . . . . . . . . . . . . . . . . . . 10

2.2.6 Monitoramento . . . . . . . . . . . . . . . . . . . . . . . . . 10

2.2 .7 Contabilidade . . . . . . . . . . . . . . . . . . . . . . . . 11

2.2 .8 Serviços centrais . . . . . . . . . . . . . . . . . . . 11

2.3 Nuvens computacionais . . . . . . . . . . . . . . . . . . . . . 13

2.3 .1 Armazenamento de dados . . . . . . . . . . . . . . . . . . . . . . 14

2.4 Segurança . . . . . . . . . . . . . . . . . . . . . . 14

2.4.1 Segurança em federações computacionais . . . . . . . . . . . . . . . . . 15

2.4 .2 Infraestrutura de chave pública . . . . . . . . . . . . . . . 16

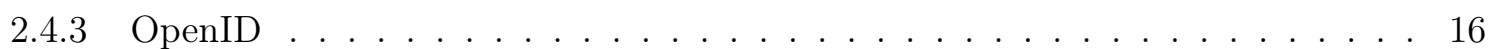

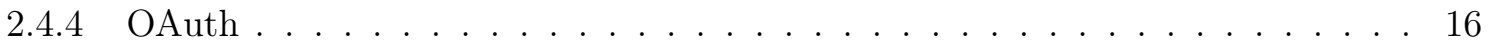

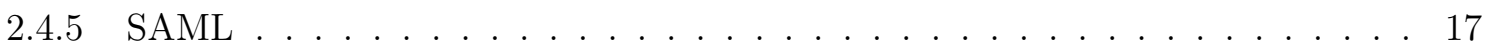

3 Panorama atual $\quad 18$

3.1 Nuvens computacionais . . . . . . . . . . . . . . . . . . . . . . 18

3.1 .1 Serviços . . . . . . . . . . . . . . . . . . . . . . 18

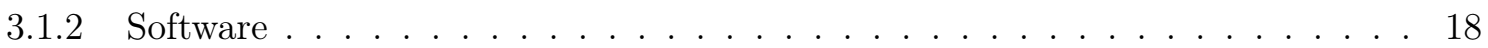


3.1.3 Padronização . . . . . . . . . . . . . . . . . . . . . . . . . . . . 18

3.1.4 Bibliotecas e serviços de abstração . . . . . . . . . . . . . . . . . . . 21

3.1.5 Análise das soluções existentes . . . . . . . . . . . . . . . . . . . . 21

4 Arquitetura proposta 23

4.1 Requisitos . . . . . . . . . . . . . . . . . . . . 23

4.1 .1 Autonomia local . . . . . . . . . . . . . . . . . . . . 23

4.1 .2 Descentralização . . . . . . . . . . . . . . . . . . . . . 23

4.1 .3 Resiliência . . . . . . . . . . . . . . . . . . . . . . 23

4.1 .4 Manutenção . . . . . . . . . . . . . . . . . . . . . . . . 24

4.1 .5 Usabilidade . . . . . . . . . . . . . . . . . . . . . . . . . 24

4.1 .6 Segurança . . . . . . . . . . . . . . . . . . . . 24

4.1 .7 Flexibilidade . . . . . . . . . . . . . . . . . . . . 25

4.2 Organização e agentes . . . . . . . . . . . . . . . . . . . . 25

4.2 .1 Grupos de pesquisa . . . . . . . . . . . . . . . . . . . . . 25

4.2 .2 Grupos de recursos . . . . . . . . . . . . . . . . . . 26

4.2 .3 Operação central . . . . . . . . . . . . . . . . . . . . . . . . . . 27

4.2 .4 Conselho gestor . . . . . . . . . . . . . . . . . . . . 27

4.3 Componentes e protocolos . . . . . . . . . . . . . . . . . . . 27

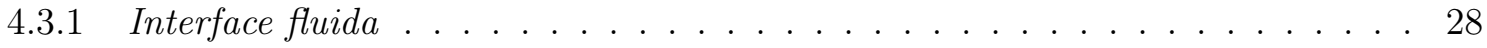

4.3.2 Simplicidade ao invés de funcionalidade . . . . . . . . . . . . . . . . 28

4.3.3 Segurança, autenticação e autorização . . . . . . . . . . . . . . . . 28

4.3 .4 Computação, dados e abstração . . . . . . . . . . . . . . . . . . . . . . . 29

4.3.5 Registro, monitoramento e contabilidade . . . . . . . . . . . . . . . 29

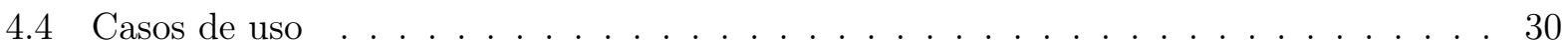

$5 \quad$ Implementação e resultados $\quad 32$

5.1 Implementação de teste . . . . . . . . . . . . . . . . . . . . . . . . . 32

5.1 .1 Ambiente . . . . . . . . . . . . . . . . . . . . 33

$5.1 .2 \quad$ Etapas . . . . . . . . . . . . . . . . . . . . . . 33

5.2 Resultados . . . . . . . . . . . . . . . . . . . . . 34

6 Conclusão $\quad 36$

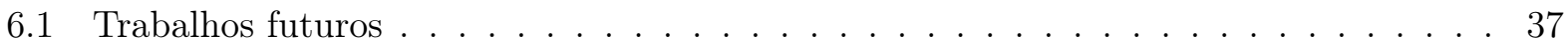

$\begin{array}{ll}\text { A Programa de teste } & 39\end{array}$

Referências Bibliográficas $\quad 41$ 


\section{Lista de Abreviaturas}

AC Autoridade Certificadora

API Application programming interface

CORBA Common Object Request Broker Architecture

DNS Domain Name System

EGI European Grid Infrastructure

FTP File Transfer Protocol

GPGPU General-purpose graphics processing unit

GRL Gerenciador de Recursos Local

GSI Grid Security Infrastructure

HTTP Hypertext Transfer Protocol

HTTPS Hypertext Transfer Protocol over Secure Socket Layer

IaaS Infrastructure as a Service

ICP Infraestrutura de Chaves Públicas - Public Key Infrastructure, em inglês

IdP Identity Provider

JSON JavaScript Object Notation

LDAP Lightweight Directory Access Protocol

LHC Large Hadron Collider

MV Máquina Virtual

OCCI Open Cloud Computing Interface

OGF Open Grid Forum

OSG Open Science Grid

ReST Representational State Transfer

SAML Security Assertion Markup Language 
SSL Secure Sockets Layer

SOAP Simple Object Access Protocol

TLS Transport Layer Security

VO virtual organization

WLCG Worldwide LHC Computing Grid

X.509 um padrão para criação de sistemas de ICP

XML EXtensible Markup Language 


\section{Lista de Figuras}

2.1 Exemplo de organização de recursos em uma federação (fonte: OpenScienceGrid) . . 5

2.2 Arquitetura do Globus Toolkit 5. (fonte: Globus) . . . . . . . . . . . . . . . . 6

2.3 Tela de monitoramento RSV . . . . . . . . . . . . . . . . . . . . . . . 10

2.4 Tela de monitoramento RSV . . . . . . . . . . . . . . . . . . . 11

2.5 Tela do sistema Gratia. . . . . . . . . . . . . . . . . . . . . . 12

2.6 Modelos de provisionamento (crédito: Armbrust at al.) . . . . . . . . . . . 13

3.1 Arquitetura do Fedcloud. (fonte: EGI) . . . . . . . . . . . . . . . . . . . . 19

4.1 Estrutura da federação . . . . . . . . . . . . . . . . . . . . . . . 26

4.2 Caso de uso 1: Grupo de pesquisa pequeno ou usuário iniciante . . . . . . . . . . . 30

4.3 Caso de uso 2: Grupo de pesquisa de grande porte . . . . . . . . . . . . . . 31

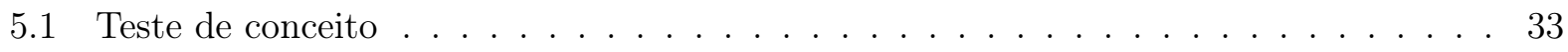

5.2 Etapas do teste de conceito . . . . . . . . . . . . . . . . . . 34

6.1 Disponibilidade dos componentes . . . . . . . . . . . . . . . . . . . . 37 


\section{Capítulo 1}

\section{Introdução}

A forma como são realizadas pesquisas científicas tem evoluido significativamente em diversas áreas do conhecimento. Em grande parte, essa mudança se deve à maior oferta de ferramentas computacionais. Em muitas áreas, a utilização desses recursos ainda está em fase de adoção, sendo uma ferramenta auxiliar ou complementar. Em outros, já é indispensável. Seja qual for o caso, o amplo desenvolvimento de tecnologias computacionais e o constante aumento de sua capacidade permitem tanto a simulação de modelos mais complexos com uma redução no custo. Essa expansão da pesquisa cientifica que faz uso intensivo da computação é muitas vezes referida como eScience (Foster, 2011).

Ao longo do tempo, foram criadas e implementadas diversas arquiteturas computacionais buscando atender as necessidades de processamento de rotinas científicas. Essas arquiteturas evoluíram, partindo de supercomputadores vetoriais, para clusters, e mais recentemente, grades computacionais. Essas, utilizando-se da consolidação das redes entre centros de pesquisas e universidades, expandiu o conceito de computação distribuída para além de um único cluster.

Recentemente emergiu uma nova forma de disponibilizar recursos computacionais, a qual tem sido referida com cloud computing ou nuvens computacionais. Muito atrelada ao conceito de aaS (as a service, como serviço), disponibiliza computação ou armazenamento como serviço sobre demanda (Armbrust et al., 2009). Essa tecnologia, possibilitada pelo uso de virtualização e, assim como nas grades computacionais, utilização de redes de alta capacidade, tem atraído grande interesse, tanto acadêmico como comercial.

Esse novo modelo foi amplamente adotado pelos ganhos econômicos que tem gerado a inúmeras organizações. Partindo do princípio que as demandas a serviços são variáveis (variam com o horário do dia, por exemplo), consegue-se obter ganhos muito expressivos ao consolidar serviços ociosos e, sob demanda, alocar recursos apenas quando necessário.

\subsection{Motivação}

"A comunidade científica tem hoje uma oportunidade sem precedentes para realizar uma profunda transformação na forma como indivíduos e grupos abordam a pesquisa (descoberta). As forças propulsoras são um conjunto novo de capacidades relacionadas que, quando coordenadas, podem acelerar dramaticamente o processo de descoberta: a maior disponibilidade de dados massivos, computadores exponencialmente mais rápidos, redes de alta velocidade e fortes colaborações interdisciplinares." (Foster, 2011)

A demanda por processamento computacional raramente é constante, variando significativamente ao longo do desenvolvimento de um projeto de pesquisa. Há momentos em que pode existir uma grande demanda. Por outro lado, caso os recursos sejam dimensionados para esse pico, ficarão ociosos durante grande parte do tempo, além de incorrer em um alto custo de aquisição. A computação em grade trouxe uma nova perspectiva acerca do uso dos recursos computacionais, ao permitir que diversas instituições colaborem compartilhando recursos. Esse modelo se mostra 
extremamente vantajoso considerando a flutuação de demanda por processamento computacional (Cirne et al., 2006).

O compartilhamento de recursos pode se dar de forma compulsória, por exemplo quando alguns grupos de pesquisa se juntam para buscar financiamento a um recurso computacional, ou oportunístico, isto é, apenas quando o recurso estiver ocioso da utilização por seus proprietários, será disponibilizado aos demais interessados.

Ambos os modelos são vantajosos para todos os envolvidos. Quando os grupos se juntam, conseguem pleitear melhores equipamentos e dividem encargos com a manutenção do sistema, que geralmente inclui uma equipe técnica especializada. Para as agências de fomento à pesquisa essa abordagem é interessante pois diminui o risco do recurso ser subutilizado. Os pequenos grupos e grupos em formação passam a ter acesso, mesmo que com baixa prioridade, a grandes recursos computacionais. Por fim, o compartilhamento entre grandes centros pode melhor acomodar os picos de demanda.

Os sistemas de nuvem introduzem uma série de novas possibilidades, com grande enfase na virtualização dos recursos. Por exemplo, nuvens permitem aplicações interativas, algo muito limitado no modelo de grades computacionais.

A arquitetura original das nuvens computacionais utiliza um modelo de cliente e servidor, onde os serviços são prestados por um provedor altamente centralizado. Quando o acesso a uma nuvem pode ser contratado como serviço prestado por empresas especializadas, essa é denominada como uma nuvem publica. Em contra partida, quando uma organização opta por criar a sua própria nuvem para atender a demanda interna, essa é denominada nuvem privada.

Com a popularização da utilização de nuvens privadas dentro de organizações acadêmicas ou de pesquisa, torna-se interessante compartilhar esses recursos com outras instituições. Por exemplo, uma organização pode criar uma pequena nuvem para atender aos seus projetos. Quando esses recursos estão ociosos, ela pode disponibilizar esses recursos a seus parceiros. Quando necessita de mais recursos do que os disponíveis no próprio sistema, ela pode utilizar recursos de parceiros.

Mecanismos desse tipo são os que formam o cerne das federações de grades computacionais. E é de grande interesse disponibilizar mecanismos análogos para as nuvens computacionais, permitindo também a criação de federações (Foster et al., 2008) (Simons, 2012).

Exemplo concreto é o compartilhamento de recursos entre universidades. Suponha que duas universidades possuam nuvens privadas. Visando a melhor utilização dos recursos, elas estabelecem um parceria para compartilhar recursos ociosos. Um usuário de uma universidade precisa dispor de ferramentas que o permita utilizar recursos da outra universidade. Isso inclui, por exemplo, permitir que ele se autentique nesses recursos sem ser manualmente cadastrado no sistema dessa universidade.

Porém, apesar dos crescentes investimentos nas plataformas de nuvem por parte do meio acadêmico e o entendimento dos benefícios em se compartilhar os recursos, a exemplo das grades computacionais, atualmente não existe nenhum mecanismo, em produção, que permita a criação de uma federação de nuvens computacionais.

\subsection{Objetivo}

Esse trabalho contribui para o desenvolvimento de tecnologias de computação em nuvem abordando um tema pouco explorado, mas que é de grande importância para a colaboração acadêmica ao permitir o compartilhamento, e por consequência, o uso otimizado de recursos computacionais.

O objetivo é apresentar uma arquitetura de interoperação para nuvens computacionais que permita a criação de federações de nuvens computacionais acadêmicas.

Sob a perspectiva atual do eScience, a importância em dominar a tecnologia de nuvens computacionais é indiscutível. Estudar como essas instancias de processamento podem interoperar tem um papel fundamental para otimizar a disponibilização desses recursos. Em especial em países como o Brasil, onde a grande maioria dos investimentos financeiros para aquisição de recursos computacionais advém de verbas públicas, fazer o melhor uso possível e evitar sua ociosidade tem uma 
importância social fundamental e podem auxiliar significativamente o desenvolvimento de pesquisas científicas.

A dificuldade em se atingir esse objetivo está na sutileza de propor um padrão de interoperação que:

- mantenha a autonomia dos federados;

- seja robusto;

- seja de fácil utilização, apesar da inerente complexidade;

- permita, e se beneficie, da contínua evolução das tecnologias de nuvem.

\subsection{Metodologia}

Para atingir seu objetivo, esse trabalho parte de um amplo estudo acerca das ferramentas para a criação de nuvens computacionais e padrões já existentes. Estuda, também, o trabalho realizado por outros projetos com objetivos similares.

Buscando compreender a estrutura de federações computacionais, e as diversas interações entre os seus agentes e componentes, também são analisados os elementos das estruturas de grades computacionais, sua evolução histórica, e o seu papel equivalente a ser desempenhado nas nuvens.

Com base nessa analise, é proposta um arquitetura para criação de nuvens computacionais. Essa arquitetura visa reutilizar ao máximo componentes já existentes e, ao mesmo tempo, permitir a evolução dos componentes envolvidos.

Por fim, uma instância de demonstração dessa plataforma é implementada, com o objetivo de demostrar a viabilidade concreta dessa proposta.

\subsection{Organização}

Esse trabalho está organizado em outros 5 capítulos. No capítulo 2, são apresentados alguns conceitos utilizados nos decorrer do projeto. Como esse trabalho é amplamente baseado em algumas tecnologias de computação em grade que podem não ser de amplo conhecimento de todos os leitores, grande parte desse capitulo é dedicada a esclarecer alguns detalhes de funcionamento dessa tecnologia. Também são explicados conceitos de nuvens computacionais e de segurança de sistemas distribuídos.

No capítulo 3 é apresentado o panorama atual das diversas tecnologias de nuvens, e as iniciativas que buscam a padronização e interoperação desses sistemas. Também é apresentado um resumo dos componentes das estruturas de grades como estão compostas atualmente. No capítulo 4 está detalhada a proposta de arquitetura para a criação de federações de nuvens computacionais acadêmicas, respeitando todos os requisitos de autonomia das federações, buscando a efetividade de uma solução concreta com a possibilidade de evolução de uma plataforma ainda em amplo desenvolvimento.

O capítulo 5 relata o processo de criação de uma instância de demonstração dessa arquitetura, com enfase no seu maior desafio, a autenticação e autorização distribuídas. Por fim, o capítulo 6 contém as conclusões desse trabalho. 


\section{Capítulo 2}

\section{Conceitos}

\subsection{Federações de recursos computacionais}

Ao longo do tempo foram criadas e implementadas diversas arquiteturas computacionais buscando atender às necessidades de processamento de rotinas científicas. Essas arquiteturas evoluíram, partindo de supercomputadores vetoriais, para clusters, e mais recentemente, grades computacionais. Essas, utilizando-se da consolidação das redes entre centros de pesquisas e universidades, expandiu o conceito de computação distribuída para além de um único cluster.

Essas grades computacionais, ou grid computing, são sistemas compostos por diversos recursos computacionais distribuídos, como servidores de processamento e de armazenamento de dado, mas que pertencem a domínios administrativos distintos. É importante observar que ao se considerar domínios administrativos distintos está se construindo mais que a simples união de clusters. A união dos recursos de domínios distintos é chamada de federação.

Uma das grandes contribuições desse modelo de computação em grade foi a perspectiva de compartilhar recursos. É possível observar que a demanda de cada grupo de pesquisa, ou mesmo em cada centro de computação, é sazonal, tipicamente alternando algumas semanas de altíssima demanda e períodos de baixa demanda por processamento. Ao compartilhar recursos em escala global, obteve-se uma otimização da utilização de recursos.

Um dos princípios fundamentais que norteiam o conceito de federação adotado por essas estruturas é a da autonomia dos sites. Cada site é mantido e administrado por sua equipe local. Isso decorre de uma implicação política, provavelmente foi uma fonte local que financiou a aquisição e manutenção desses equipamentos, e uma implicação técnica: usar equipes locais de administradores para não sobrecarregar uma estrutura central de administração.

Dessa forma, recursos podem ser incluídos na federação sem que seja cedido qualquer tipo de acesso de administrador dos recursos. O resultado é uma compilação heterogênea de recursos. Se adequadamente explorada, essa dispersão (também geográfica) pode ser usada como vantagem, ao criar um sistema distribuído mais resiliente a falhas, por depender de uns poucos pontos centrais.

E existe uma terceira classe: os serviços centrais ou centro de operação. São um conjunto de serviços único dentro da federação providos de forma central, de forma a organizar o funcionamento da mesma. Por exemplo, um diretório indicando quais são os sites participantes. Teoricamente seria possível criar sistemas totalmente descentralizados, mas por uma razão prática, adotam-se esses serviços centrais desde que eles fiquem restritos à organização da federação e não violem a autonomia dos sites.

Ao se tratar aqui do problema de federação, que envolve um número arbitrário de parceiros em cooperação, também se soluciona o caso específico onde duas organizações buscam compartilhar recursos. 


\subsubsection{Organização}

Geralmente os atores envolvidos em um sistema distribuído desse tipo (seja grade ou seja nuvem) são: usuários e os recursos computacionais. Os usuários são agrupados em grupos de usuários e sua relação com o grupo é estabelecida através de papéis. Já os serviços são agrupados em sites.

Os usuários podem ser os pesquisadores (usuários finais), administradores do sistema ou coordenadores. Nas estruturas de grade de referência, eles são agrupados em organizações virtuais (virtual organization (VO)). Essas organizações geralmente se formam tendo um projeto de pesquisa comum. Dessa forma, pesquisadores de diferentes instituições mas pertencentes ao mesmo grupo de pesquisa são reunidos em um único grupo. Essa organização também é frequentemente mais natural da perspectiva de distribuição de pesquisa e financiamento.

Os papéis (roles) são as funções que cada integrante desempenha dentro do seu grupo. É comum existirem usuários normais, pessoas responsáveis pela administração e coordenadores. Cada um desses papéis representa um conjunto diferente de autorizações. Por exemplo, um coordenador pode incluir e excluir membros do grupo e um administrador pode instalar aplicativos ou gerenciar processos que não os dele.

Os recursos computacionais são agrupados em sites, e representados por seus pontos de interface (endpoint). Múltiplos recursos, como um cluster inteiro, podem ser representados por um único ponto de interface. Por outro lado, um único recurso, pode também ser exposto através de múltiplas interfaces, para expor mais de um protocolo ou prover alta disponibilidade. Os serviços são agrupados em sites, indicando que aquele conjunto de recursos é gerido pelo mesmo grupo de administradores e, geralmente, financiadores. Outros agrupamentos também são possíveis, como exemplificado na figura 2.1, que apresenta o modelo utilizado pelo Open Science Grid (OSG).

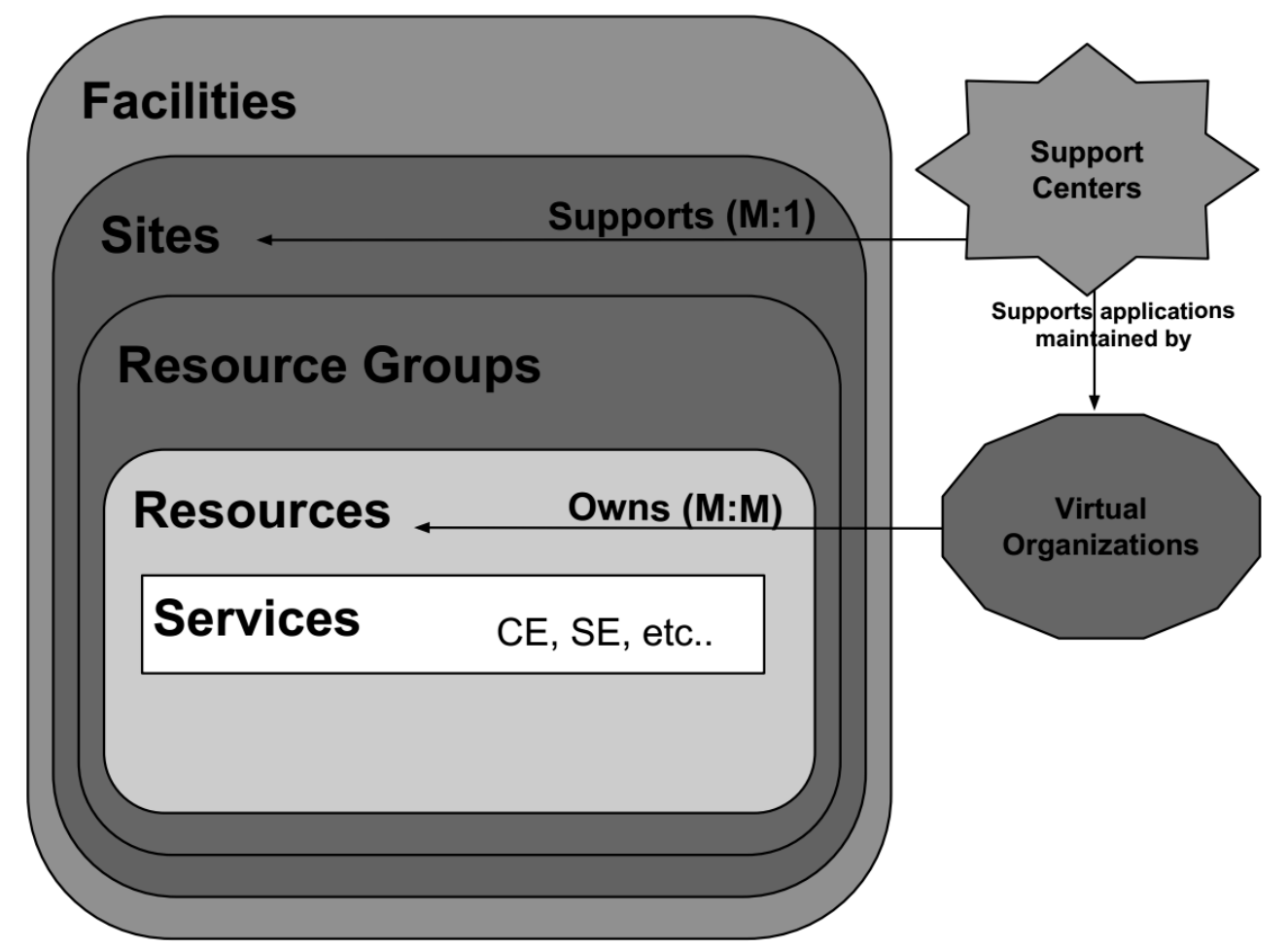

Figura 2.1: Exemplo de organização de recursos em uma federação (fonte: OpenScienceGrid)

\subsection{Grades computacionais}

A comunidade de física de altas energias foi a primeira a utilizar essa tecnologia em larga escala, construindo sistemas que englobam dezenas de países e centenas de universidades (Leake, 2012). Os 
dois middlewares ${ }^{1}$ de computação em grade mais utilizados atualmente são o OSG, uma iniciativa norte-americana, e o European Grid Infrastructure (EGI), antigo EGEE, de iniciativa europeia. Ambos são baseados no Globus Toolkit (Foster et al., 2002), padronização e implementação padrão para grades computacionais.

Como exemplo da escala desses sistemas, o OSG é composto por 116 sites de 40 instituições e executou, no ano de 2013, mais de 710 horas de processamento e transferiu 380 petabytes no mesmo período. O EGI é composto por 281 instituições em 42 países, disponibilizando mais de 352 mil núcleos de processamento, processando em média 50 milhões de simulações por mês (Pordes et al., 2010).

\subsubsection{Globus Toolkit}

Para a federação de grades computacionais foram desenvolvidos um conjunto de protocolos que permite a comunicação entre os usuários e os recursos. Esses protocolos foram padronizados no Open Grid Forum (OGF), que criou o Globus Toolkit, um conjunto de protocolos e também uma implementação de referência dos mesmos.

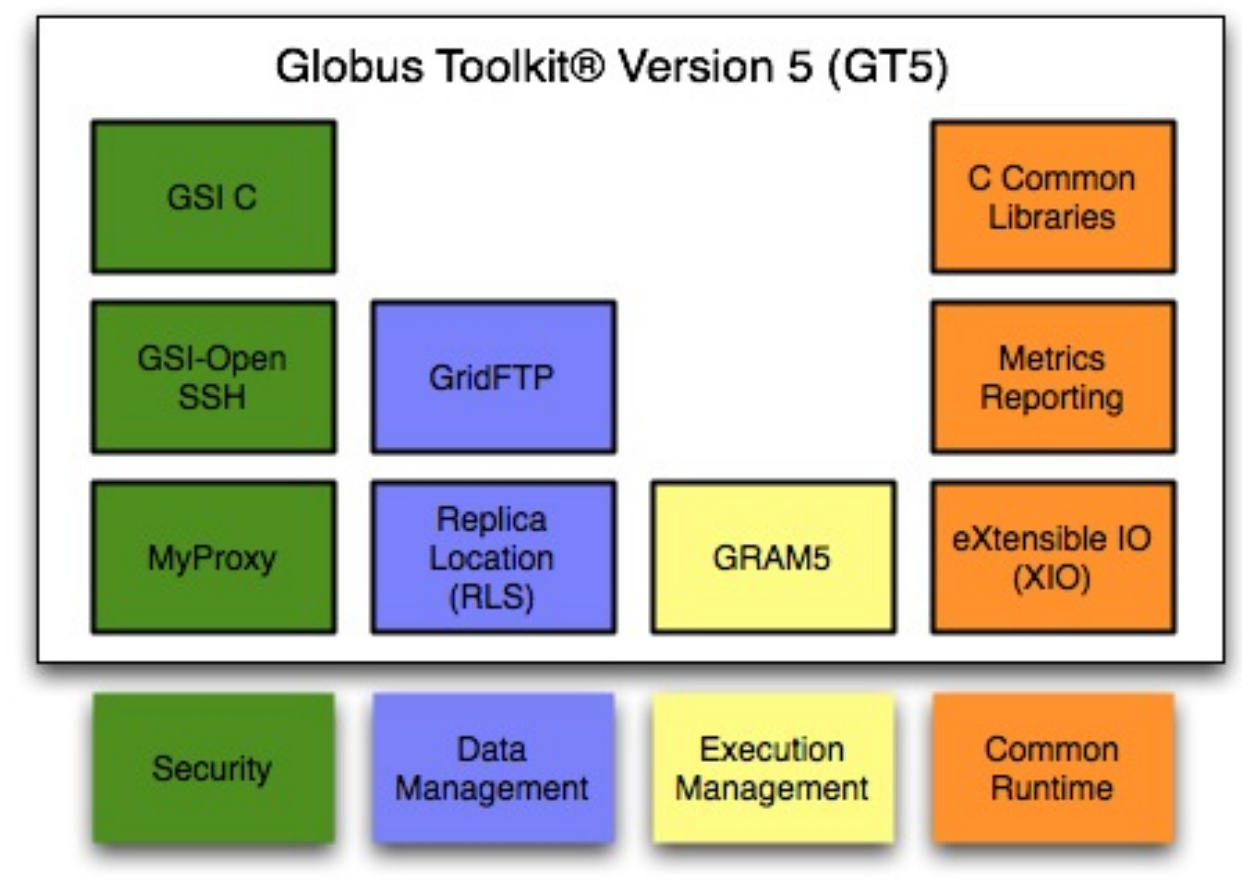

Figura 2.2: Arquitetura do Globus Toolkit 5. (fonte: Globus)

O desenvolvimento do Globus Toolkit já contou com diversas arquiteturas e tecnologias. Em especial, duas fases foram bastante representativas. A versão 2, também chamada de pre web services marca o auge do desenvolvimento usando protocolos que não utilizavam técnicas web services $(\mathrm{SOAP}+\mathrm{XML})$. Por sua relativa simplicidade, foi (e ainda é) amplamente utilizada em sistemas em produção. A versão 4 foi a versão com web services mais difundida, mas por sua inerente complexidade, não substituiu a versão 2 em muitos sites. A versão 5 , que simplifica muitas das especificações da versão 4 e torna obsoletos diversos mecanismos, tenta incorporar as vantagens da versão 2 tentando uniformizar a utilização dos protocolos (Foster, 2003). A figura 2.2 representa a arquitetura do Globus Toolkit 5 e seus componentes. No final de 2014 foi lançada a versão 6 do Globus Toolkit. Essa versão não traz mudanças de funcionalidade, apenas organiza melhor o código-fonte e o processo de compilação e é integralmente compatível com as versões 5.0 e 5.2.

\footnotetext{
${ }^{1}$ middleware (programa mediador): Conjunto de programas que permite a comunicação e o gerenciamento de recursos computacionais, geralmente aplicado a sistemas distribuídos.
} 
É importante destacar como a tecnologia escolhida para a criação de um protocolo pode ser um fator fundamental. Em especial o quanto a simplicidade, em contra-ponto a um número maior de recursos, pode determinar o sucesso de uma especificação. Por isso é fundamental entender a comunidade em que esse protocolo busca ser adotado.

O Globus Toolkit fornece blocos fundamentais para a execução de computação em grades, mas outros componentes que não estavam disponíveis nas versões iniciais tiveram que ser elaborados pelas próprias comunidades que compunham as federações. Em especial, os componentes de descoberta, monitoramento e contabilidade. As duas maiores federações, OSG e EGI, desenvolveram, cada uma, suas próprias ferramentas e serviços. Apesar da necessidade de cooperação imposta pelo Large Hadron Collider (LHC), a interoperabilidade desses componentes deixa a desejar. Quando o Globus Toolkit tentou desenvolver esses componentes para criar um padrão, incluídos na versão 4, as ferramentas anteriores já estavam arraigadas na cultura dessas comunidades. Sem conseguir apoio, o Globus Toolkit optou por remover esses componentes na versão 5, tentando mantê-la mais simples. Como resultado, a fragmentação existe até hoje.

\subsubsection{Gerenciamento de execução}

É fundamental a existência de um protocolo responsável pelo gerenciamento da execução (execution managemant) do processamento. Nas grades computacionais baseadas no Globus Toolkit, o protocolo usado é o GRAM (Globus resource allocation manager).

Esse protocolo (GRAM) abstrai o Gerenciador de Recursos Local (GRL) (LRM, em inglês), criando um mecanismo independente da configuração do cluster local. Isso permite executar processamento em lote (batch scheduling) com um único protocolo em clusters executando diferentes gerenciadores de execução, como o PBS, Torque, LSF, SLURM, OGE e Condor. O protocolo permite o envio de processo, indicando opções como o executável, argumentos, variáveis de ambiente, arquivos de entrada e a lista de arquivos que deve ser salva como arquivos de saída. Permite ainda verificar o estado do processo (se está esperando, em execução ou completo), cancelar o processamento e retirar os arquivos de saída.

As versões do GRAM 2 e 5 descrevem os processos através da RSL (Globus Resource Specification Language). Uma característica importante é permitir a especificação de novos parâmetros, não previstos na modelagem inicial. Esse recurso possibilita a evolução dos requisitos, como por exemplo a especificação de aceleradores como General-purpose graphics processing unit (GPGPU)s. A ausência desse recurso na versão 4, baseada em java webservices e esquemas EXtensible Markup Language (XML) previamente definidos foi um dos fatores que limitou a sua adesão.

Porém, ao se estender a linguagem sem padronizá-la, criando "dialetos", remove-se a homogeneidade da interface com múltiplos sistemas. Esse problema só não é mais significativo pois, apenas considerando os recursos inicialmente definidos na RSL, nem todos os escalonadores oferecem suporte completo, o que já viola a homogeneidade. Por exemplo, limites de tempo de execução, requisitos de memória e execuções paralelas utilizando memória distribuída não são amplamente suportadas.

Pela forma como o GRAM foi implementado no Globus Toolkit, sua execução é considerada pesada, sobrecarregando os escalonadores de sistemas que disponibilizam recursos de médio e grande porte (problemas de escala surgem a partir de uma centena de servidores). Para mitigar esses efeitos, geralmente são desabilitados alguns recursos, como o acesso durante a simulação a arquivos de saída, a utilização de "job-managers" para responder em uma única consulta o estado de múltiplos processos e a utilização do SEG (Scheduler Event Generator), que evita consultar diretamente o escalonador local para identificar o estado dos processos.

Uma alternativa ao GRAM foi desenvolvida pela iniciativa de grade europeia, nomeada de CREAM (Computing Resource Execution And Management) (Andreetto et al., 2006), com o objetivo de ser leve (lightweight) e simples. Testes demonstraram uma escalabilidade muito superior ao GRAM, porém até o momento sua adoção é limitada a sites europeus. 


\section{Pilot Jobs}

A técnica de envio chamada pilot jobs começou a ser utilizada por algumas das colaborações do LHC no Worldwide LHC Computing Grid (WLCG) em meados da década de 2000, dominou a evolução dos sistemas de envio de processos para as grades computacionais. Hoje é amplamente utilizada, já sendo a maioria dos processos nas federações OSG e EGI. Ela consiste em não enviar o processo a ser executado diretamente ao cluster, mas ao invés disso enviar um processo de controle (pilot job) que aguardará na fila e, ao iniciar a sua execução, irá consultar um serviço central requisitando o real processamento para início imediato.

Para esse sistema funcionar, é necessário que o usuário disponha de um serviço central para gerenciar esse meta fila. Um serviço desse tipo é geralmente disponibilizado por cada grupo de pesquisa (VO), mas é também um serviço prestado pelo grupo de operações das federações para colaborações menores. Algumas das plataformas para utilizar esse tipo de workflow são PANDA (De et al., 2012) e o GlidinWMS (Sfiligoi, 2008).

Esse tipo de execução de processos adiciona um pouco de complexidade ao workflow, ao exigir um novo serviço intermediário. Porém, gera diversos benefícios. Ao possibilitar o envio de diversos processos pilot para diferentes recursos, permite a efetiva seleção do recurso mais disponível, possibilita uma rápida recuperação de erros e diminui alguns dos overheads que ocorrem em simulações muito curtas (poucos minutos). Também permite uma melhor priorização e contabilidade dos recursos dentro do seu escopo (geralmente um VO). As plataformas utilizadas também ajudam a abstrair as diferenças de interface dos diferentes sites, simplificando a utilização para o usuário final. Porém introduzem novos problemas, em especial, ao modelo de segurança, uma vez que o processo é executado no site final com as credenciais de segurança do processo piloto, e não do usuário² .

É curioso notar que o surgimento da técnica de processos piloto levou ao desenvolvimento de novas plataformas capazes de integrar outros recursos, como clusters locais e nuvens. Um exemplo é a ferramenta BOSCO (Grid, 2014).

\subsubsection{Armazenamento de dado}

Tão importante quanto o gerenciamento do processamento é um eficiente gerenciamento de dados. E nesse aspecto a computação em grade tem uma indiscutível reputação. Essa capacidade tem sido moldada pela demanda da comunidade de Física de Altas Energias, para o LHC e outros projetos, criando estruturas otimizadas para lidar com grandes volumes de dados. Conjuntos de dados com alguns terabytes e sites com petabytes de capacidade são comuns nessas estruturas. Em um ano, a estrutura do OSG apenas movimentou 376 petabytes de dados (somente considerando datasets).

Essas transferências, em uma estrutura de grade utilizando Globus, são feitas utilizando dois protocolos: SRM e GridFTP. O protocolo SRM (Storage Resource Manager) é um protocolo de alto nível que opera, em especial, com operações de metadado. É eficiente na listagem de arquivos e também é usado para fazer reserva de espaço. Já o protocolo GridFTP é utilizado para as transferências propriamente ditas, com um funcionamento análogo ao File Transfer Protocol (FTP). Porém, além de contar com autenticação via Grid Security Infrastructure (GSI) (certificados X.509), tem várias otimizações para a transferência de grandes volumes. Permite abrir vários canais paralelos, para otimizar a transferência e permite third party transfers, onde uma operação iniciada no sistema Z solicita a transferência direta entre X para Y. Protocolos onde só estão disponíveis operações de PUT e GET, todo o dado teria que ser enviado a $\mathrm{Z}$.

Entre as técnicas para o gerenciamento de grandes volumes de dados nas grades computacionais, os maiores grupos utilizam algum sistemas de gerenciamento de réplicas. No Globus Toolkit 4 estava disponível o RLS (Replica Location Service). Também está disponível o LFC (LCG File Catalog). Ambos funcionam como uma catálogo com referencia para múltiplas localizações onde os dados estão

\footnotetext{
${ }^{2}$ Uma forma de lidar com esse problema foi o desenvolvimento do GLExec, que permite a troca das credenciais de um processo já alocado. No entanto, ao necessitar de privilégios de administrador para ser executado, introduziu mais problemas de segurança do que resolveu.
} 
disponíveis. Outros grupos, como o experimento CMS do LHC, utiliza uma ferramenta própria para o gerenciamento dos seus dados, nesse caso o PhEDEx, que além de gerenciar as transferências e suas réplicas, tem um sistema para solicitação e aprovação de transferências. Para grupos como esse, apesar do grande avanço das redes, a transferência dos dados é tão significativa, que os processos são escalonados para onde os dados estão, e não ao contrário.

Para suportar as necessidades da computação em grade, forma desenvolvidos alguns servidores especializados. DCache, Xrootd e Bestman são os mais utilizados. O protocolo GridFTP (e por consequência, o SRM) só permitem a leitura ou escrita do arquivo de forma sequencial, não dispondo de operação de avanço (seek) ou modificações parciais (mesmo append não é suportado). Essa é uma escolha adequada para a transferência entre os sites, porém é muito limitante para o processamento efetivo dos dado no site. Por isso, as aplicações acessam esses grandes volumes de dados através de protocolos e bibliotecas específicos: xrootdfs e libdcap, no caso do Xrootd e DCache e Hadoop ou acesso POSIX no caso do Bestman, dependendo do backend. De forma geral, isso significa que não é permitido à aplicação a escrita aleatória de arquivos e, em todos os casos, as soluções dependem das escolhas de cada site e comprometendo, de forma significativa, a homogeneidade da grade.

\section{GlobusOnline}

Esse conjunto de protocolos se provou extremamente eficiente para transferências entre sites, porém sofre de um problema descrito como last mile: é fácil transferir entre dois sites, porém é muito difícil fazer com que esses dados cheguem aos usuários finais. Por se tratarem de protocolos específicos e que requerem uma estrutura de portas abertas para conexões entrantes e certificados, a sua utilização em dispositivos finais, como a estação de trabalho de um pesquisador, é muito restrita. Para circundar esse problema foi desenvolvido o GlobusOnline (Foster, 2011), um serviço que permite o usuário fazer download e uploads de arquivos diretamente a servidores de armazenamento dos sites de grade através de uma interface web e um cliente local (um servidor de GridFTP simplificado, escrito em java). Essa ferramenta foi muito bem sucedida e é utilizada no workflow de vários grupos de pesquisa.

\subsubsection{Autenticação e autorização}

Uma das grandes virtudes das grades computacionais baseadas em Globus é o seu sistema de segurança, GSI (Grid security infrastructure). Esse sistema utiliza certificados X.509 para a autenticação de usuários e servidores, e um sistema distribuído para autorização, chamado de VOMS (Virtual Organization Membership Service). Dessa forma todas as operações são realizadas através de comunicações criptografadas com as partes autenticadas. Para isso, além da utilização dos certificados X.509 convencionais, utiliza-se a extensão proxy (Tuecke et al., 2004, RFC3820). Isso permite que o processo, executado no interior do cluster, possa assinar transferências de arquivos, por exemplo os arquivos de saída, em nome do usuário.

Porém, esse modelo de segurança foi construído com requisitos de décadas atrás. Por exemplo, ele não depende da contínua disponibilidade dos sites ou dos servidores de autorização, podendo funcionar offline por diversas horas. Sobre a perspectiva moderna, esse modelo de segurança tem uma manutenção bastante onerosa. A começar que, para seu funcionamento, é preciso que todas as partes possuam certificados. A demanda por certificados é tão grande que é utilizada uma estrutura de PKI independente da comercia, conhecida como IGTF (International Grid Trust Federation). A criação de um certificado pode levar de horas a dias. Esse certificados também contam com uma validade típica de um ano, onde precisam ser manualmente substituídos. Além disso, os servidores precisam de nomes reversos (reverse $D N S$ ) válidos (informação presente no certificados). Esses requisitos não são adequados a um sistema dinâmico como o proposto pelas nuvens computacionais.

A gerência de certificados pelos usuários finais também não é simples, apesar de diversos esforços para simplificar esse trabalho. Entre os mais importantes está o MyProxy, servidor criado para facilitar o armazenamento e distribuição dos certificados, utilizando métodos de autenticação mais diretos. 


\subsubsection{Registro e descoberta}

Para o funcionamento de uma federação também é necessário existir um mecanismo de registro e descoberta. Ele consiste de um diretório que possa ser consultado indicando quais são os sites disponíveis dentro daquela federação e suas características. Isso permite que um sistema de gerenciamento de processos ou de dados identifique potenciais recursos, filtrando pelas características desejadas. Como referência, a estrutura usada no OSG está na figura 2.1.

O mecanismo proposto pelo Globus é o GLUE (Grid Laboratory Uniform Environment) schema, que é uma definição da estrutura de informações (Zeilenga, 2006, RFC4510) a ser armazenado e disponibilizado em um banco de dados BDII (Berkeley Database Information Index), que consiste em uma banco de dados LDAP com um mecanismo de atualização externo e distribuído. Dessa forma o Globus apenas definiu um formato. Já o serviço, sendo ele servidor LDAP com as informações, é mantido como parte dos serviços centrais da federação, junto com serviços de monitoramento, suporte, contabilidade, entre outros.

Como no OSG é muito difundida a utilização do escalonador de processos Condor, a informação contida no diretório LDAP também é disponibilizada no formato ReSS, adequando para consumo direto nesse software.

\subsubsection{Monitoramento}

A função do sistema de monitoramento é avaliar continuamente o estado de diversos componentes da complexa coleção de serviços que é uma federação. Um bom sistema de monitoramento auxilia muito a depurar erros e a identificar de forma prematura problemas. É importante destacar algumas diferença com o serviço de registro e descoberta. Este mantém uma base de dados que muda com uma frequência menor, geralmente através de operações manuais. Os sistemas de monitoramento são executados continuamente, alguns a cada hora, e por tanto tem uma natureza mais dinâmica. Muitas vezes, o sistema de monitoramento também atua de forma ativa, enviando processos e transferências de teste, para avaliar o bom funcionamento do sistema.

Historicamente, esse papel tem ficado a cargo de cada federação de grade computacionais desenvolver as suas ferramentas. A consolidação desses dados é feito por um serviço central. Algumas federações utilizam como base a plataforma Nagios. É o caso do EGI, que utiliza Nagios com um conjunto de métricas desenvolvida por essa federação batizado de SAM (Service Availability Monitoring). O OSG desenvolveu uma ferramenta chamada $R S V$ (Resource and Site Validation) que ativamente testa vários componentes, incluindo a execução de processos de teste, e reporta para uma base de dados central, que através desse histórico é capaz de calcular a disponibilidade dos sites. A figura 2.3 mostra o histórico de disponibilidade de determinado recurso, mantido em um serviço centralizado. A figura 2.4 mostra uma página de status local, exibindo as métricas avaliadas localmente e sua atual condição.

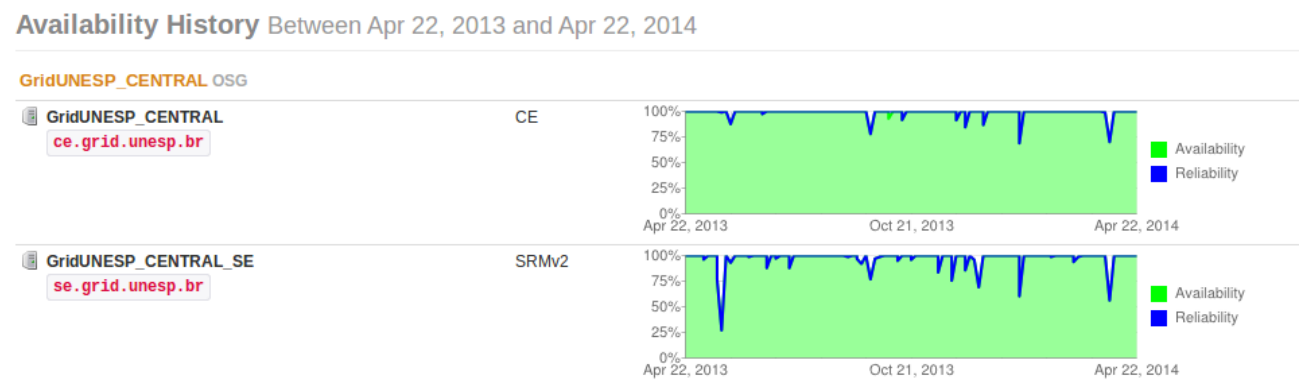

Figura 2.3: Tela de monitoramento $R S V$. 


\begin{tabular}{|c|c|c|c|c|}
\hline \multicolumn{5}{|c|}{ RSV Status - 2014-04-22 02:59:45 } \\
\hline \multicolumn{5}{|c|}{ Note: This page is for local reference only. If your site participates in WLCG availability you can view your status at http://myosg.grid.iu.edu. } \\
\hline \multicolumn{5}{|l|}{ Frequently Asked Questions } \\
\hline \multicolumn{5}{|l|}{ Host: access.grid.unesp.br } \\
\hline Metric & Last Executed & Enabled? & Next Run Time & Status \\
\hline org.osg.globus.gridftp-simple & 2014-04-22 02:08:32 BRT & YES & 2014-04-22 03:08:00 BRT & $\mathrm{OK}$ \\
\hline \multicolumn{5}{|l|}{ Host: ce.grid.unesp.br } \\
\hline Metric & Last Executed & Enabled? & Next Run Time & Status \\
\hline org.osg.batch.jobmanagers-available & 2014-04-21 04:59:20 BRT & YES & 2014-04-22 04:59:00 BRT & OK \\
\hline org.osg.certificates.cacert-expiry & 2014-04-22 00:15:21 BRT & YES & 2014-04-22 06:15:00 BRT & $\mathrm{OK}$ \\
\hline org.osg.certificates.crl-expiry & 2014-04-22 00:30:21 BRT & YES & 2014-04-22 06:30:00 BRT & WARNING \\
\hline org.osg.general.java-version & 2014-04-22 00:47:20 BRT & YES & 2014-04-22 06:47:00 BRT & $\mathrm{OK}$ \\
\hline org.osg.general.osg-directories-CE-permissions & 2014-04-22 02:37:21 BRT & YES & 2014-04-22 03:37:00 BRT & $\mathrm{OK}$ \\
\hline org.osg.general.osg-version & 2014-04-22 02:47:21 BRT & YES & 2014-04-22 03:47:00 BRT & $\mathrm{OK}$ \\
\hline org.osg.general.ping-host & 2014-04-22 02:47:00 BRT & YES & 2014-04-22 03:07:00 BRT & $\mathrm{OK}$ \\
\hline org.osg.general.vo-supported & 2014-04-21 18:54:21 BRT & YES & 2014-04-22 06:54:00 BRT & $\mathrm{OK}$ \\
\hline org.osg.globus.gram-authentication & 2014-04-22 02:31:01 BRT & YES & 2014-04-22 03:31:00 BRT & $\mathrm{OK}$ \\
\hline org.osg.globus.gridftp-simple & 2014-04-22 02:08:32 BRT & YES & 2014-04-22 03:08:00 BRT & OK \\
\hline org.osg.gratia.metric & 2014-04-22 02:23:20 BRT & YES & 2014-04-22 03:23:00 BRT & $\mathrm{OK}$ \\
\hline org.osg.gratia.pbs & 2014-04-22 02:49:20 BRT & YES & 2014-04-22 03:49:00 BRT & $\mathrm{OK}$ \\
\hline org.osg.local.hostcert-expiry & 2014-04-22 01:40:00 BRT & YES & 2014-04-23 01:40:00 BRT & $\mathrm{OK}$ \\
\hline org.osg.local.httpcert-expiry & 2014-04-22 01:24:00 BRT & YES & 2014-04-23 01:24:00 BRT & $\mathrm{OK}$ \\
\hline \multicolumn{5}{|l|}{ Host: se.grid.unesp.br } \\
\hline Metric & Last Executed & Enabled? & Next Run Time & Status \\
\hline org.osg.globus.gridftp-simple & 2014-04-22 02:08:31 BRT & YES & 2014-04-22 03:08:00 BRT & OK \\
\hline \multicolumn{5}{|l|}{ Host: se.grid.unesp.br:8443 } \\
\hline Metric & Last Executed & Enabled? & Next Run Time & Status \\
\hline org.osg.srm.srmcp-readwrite & 2014-04-22 02:28:50 BRT & YES & 2014-04-22 03:28:00 BRT & OK \\
\hline org.osg.srm.srmping & 2014-04-22 02:53:11 BRT & YES & 2014-04-22 03:13:00 BRT & OK \\
\hline
\end{tabular}

Figura 2.4: Tela de monitoramento $R S V$.

\subsubsection{Contabilidade}

O serviço de contabilidade não é crítico ao funcionamento da federação, mas sua presença é de interesse estratégico. Mesmo em situações onde não haverá compensação financeira, oferecer um serviço que indique como os recursos foram utilizados é indispensável para diversos grupos, que precisaram prestar contas a agências de fomento e outros financiadores. Esse serviço deve oferecer os dados de forma clara e precisa, preferencialmente incluindo a geração de gráficos.

Para essa funcionalidade são necessários dois componentes: os coletores locais e o serviço de agregação. Nas estruturas de grade, os coletores são rotinas periódicas que analisam os registros (logs) dos escalonadores locais e enviam em um formato patronizado para o serviço de agregação. Já o serviço de agregação consolida a informação, e gera os relatórios e gráficos de utilização global.

Um exemplo é o Gratia(Canal, 2011), usado no OSG, que faz a contabilidade, tanto de processamento, como de transferências de dados. A figura 2.5 mostra o exemplo de um relatório produzido com a ferramenta, indicando a utilização de recursos por VO. Esse é um serviço desenvolvido exclusivamente para essa federação e altamente personalizado para características das grades. Uma adaptação para as nuvens seria bastante trabalhosa.

\subsubsection{Serviços centrais}

Grande parte do mérito da criação e manutenção de uma federação está em alguns serviços prestados de forma centralizada por uma equipe dedicada a organizar a federação. Na estrutura do OSG essa equipe é chamada de GOC (Grid Operations Center). São suas principais atribuições:

- Registro

- Monitoramento 


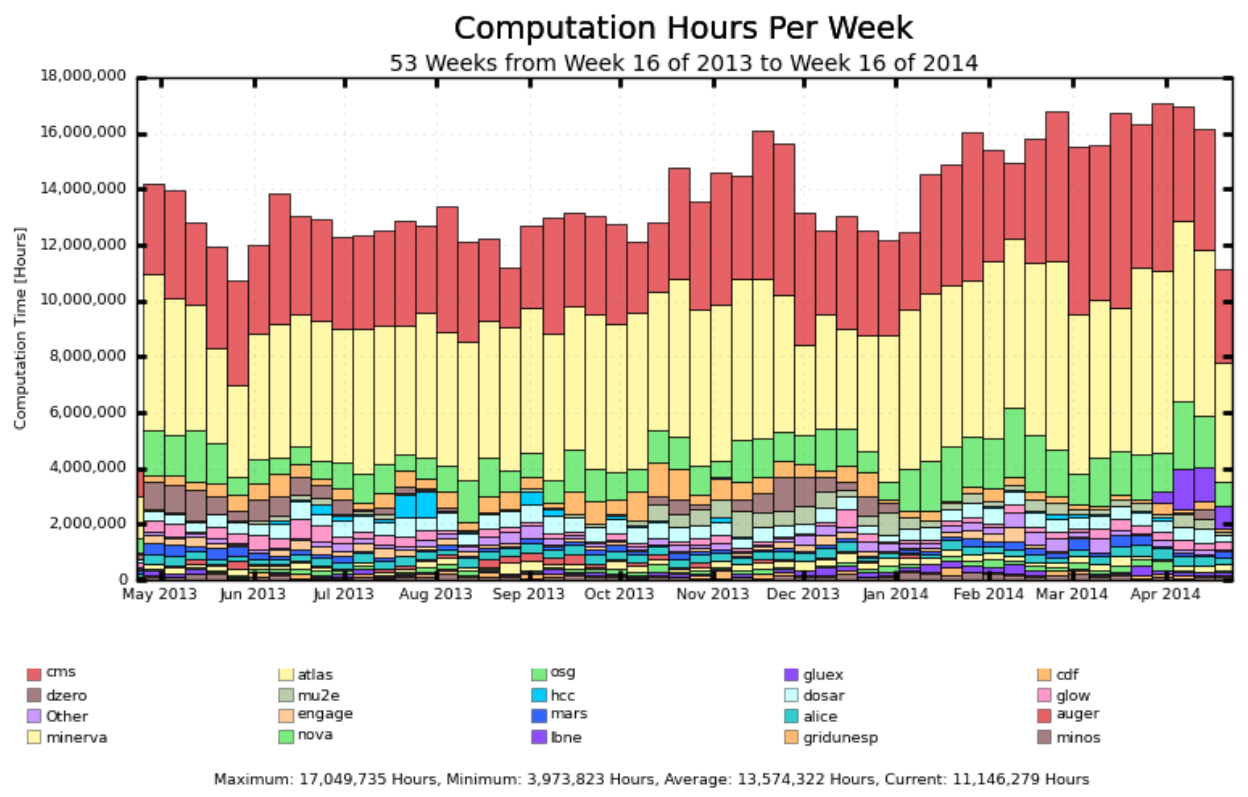

Figura 2.5: Tela do sistema Gratia.

- Contabilidade

- Distribuição de software

- Suporte de software

- Documentação

- Treinamento

- Comunicação

- Outreach

Os serviços de registro, monitoramento e contabilidade, como explicado anteriormente, consistem na criação de um repositório consolidado. A partir desse repositório central é possível realizar consultas e gerar relatórios, como de utilização ou disponibilidade. Seria possível construir uma plataforma totalmente distribuída, similar a uma rede peer-to-peer, onde os membros da federação manteriam essas informações de forma distribuída. Porém uma abordagem desse tipo é consideravelmente mais complexa e, até o momento, desnecessária.

Os serviços de distribuição de software, documentação, treinamento, comunicação são importantes para a comunidade e o seu ecossistema. A distribuição de software é necessária pois, inevitavelmente, alguns programas são criados ou modificados no escopo da federação. O suporte de software auxilia a resolução de problemas, sem sobrecarregar os desenvolvedores originais, importante principalmente por que quase toda, se não toda, a camada de software é composta por software livre.

A documentação mantêm a informações de instalação, uso e depuração da estrutura. É a referência para administradores criarem novos sites e usuários a utilizarem os recursos. Uma ferramenta de edição colaborativa, tipo wiki é a ferramenta utilizada no OSG e no EGI. O treinamento é importante para facilitar a adesão de novos membros. A comunicação ocorre através de reuniões, física ou virtuais, listas de discussão e tickets.

Finalmente, para o crescimento efetivo da comunidade, são necessárias uma série de atividades de outreach, divulgando a federação, buscando novos parceiros e auxiliando novos membros. Pela experiência recente do $O S G$, pode ser estratégico manter um grupo ( $V O$ ) para membros de grupos 
pequenos, como uma espécia de incubadora. Como a tecnologia de grades computacionais é bastante complexa, assim como a de nuvens, disponibilizar um framework pronto para uso é importante, diminuindo a curva de aprendizado e permitindo novos usuário testar a tecnologia facilmente.

Um exemplo concreto é o sistema de pilot jobs que o GOC oferece. Cada VO pode criar o seu, mas ao disponibilizar uma opção já instanciada e operacional, a experiência do usuário é simplificada. Caso o grupo cresça ou tenha requisitos não atendidos, sempre poderá desenvolver sua própria estrutura.

\subsection{Nuvens computacionais}

Recentemente foi desenvolvida uma nova forma de disponibilizar recursos computacionais, a qual tem sido referida com cloud computing ou nuvens computacionais. Muito atrelada ao conceito de aaS (as a service, como serviço), disponibiliza computação ou armazenamento como serviço sobre demanda. A computação nas nuvens se refere tanto a disponibilização de aplicativos como de infraestrutura pela internet (Armbrust et al., 2009). Essa tecnologia, possibilitada pelo uso de virtualização e, assim como nas grades computacionais, utilização de redes de alta capacidade, tem atraído grande interesse, tanto acadêmico como comercial.

Existem diversas modalidades de serviços oferecidos pelas nuvens computacionais. Os principais são IaaS (Infrastructure as a service), PaaS (Platform as a service) e SaaS (Software as a service). O termo PaaS se refere a disponibilização de uma plataforma, como um servidor de aplicações Java ou PHP. Já o termo SaaS é utilizado para indicar a oferta de uma aplicação, como um serviço de email. O termo IaaS, onde o que é oferecido é a infraestrutura, prevê a execução de máquinas virtuais, as quais o usuário pode utilizar a seu critério. Isso permite grande flexibilidade, permitindo ao usuário determinar coisas como o sistema operacional. Por ser a mais adequada ao processamento científico geral, é o foco desse trabalho. Vale salientar também que, caso a demanda de algum grupo de pesquisa requeira outras modalidades, é possível atende-las a partir da IaaS.

O termo nuvem privada se refere a serviços disponibilizados por recursos computacionais da própria organização, em oposição a nuvens públicas, ofertadas ao público geral por terceiros, em um modelo de cobrança levando em conta a utilização dos recursos (pay-as-you-go) (Armbrust et al., 2010).

Esse modelo ganhou grande adoção pelos ganhos econômicos que tem gerado a inúmeras organizações. Partindo do princípio que as demandas a serviços não são constantes (variam com o horário do dia, por exemplo), consegue obter ganhos muito expressivos ao consolidar serviços ociosos e, sobre demanda, alocar recursos apenas quando necessário. Muitas vezes o termo nuvem elástica é utilizada para reforçar essa ideia. A figura 2.6 ilustra esse fato. Estimativas mostram que a utilização média dos servidores corporativos fica entre 5 e $20 \%$ (no entanto esse levantamento não considera o perfil de utilização de processamento científico) (Armbrust et al., 2010).

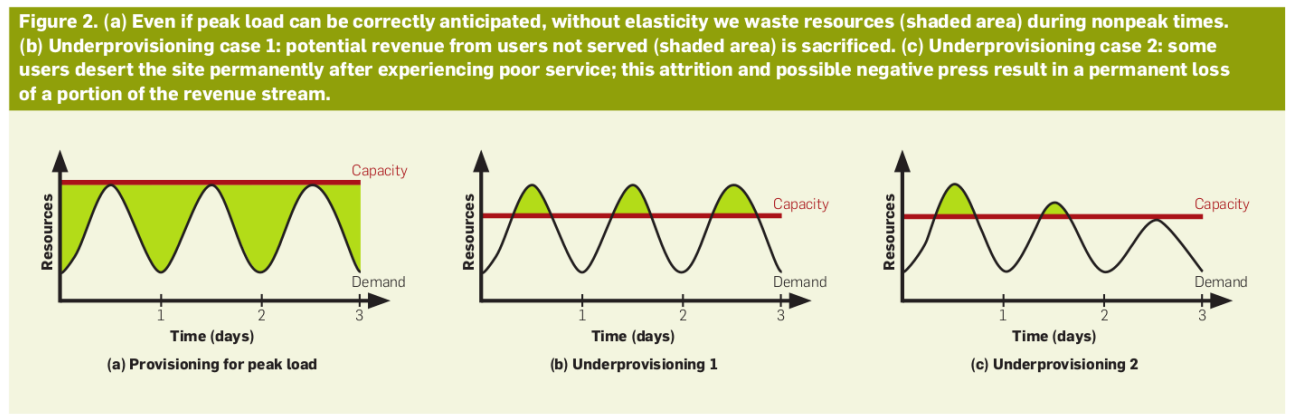

Figura 2.6: Modelos de provisionamento (crédito: Armbrust at al.)

Historicamente a Amazon (Amazon, 2013) foi a pioneira em prover Infrastructure as a Service (IaaS) e ainda é a referência nesse tipo de serviço. Em 2011 foram anunciadas novas instâncias, mais adequadas ao processamento intensivo. Desde então diversas melhorias foram implementadas. 
Em agosto de 2014, ela oferece máquinas virtuais com diversas configurações, como redes de baixa latência ou GPGPUs, por preços que variam de USD \$ 0,20 a USD \$ 0,40 por hora de um servidor com 8 núcleos, e instâncias para uso oportunístico a partir de USD \$ 0,007. Na mesma linha, a Rackable também oferta produtos semelhantes e, recentemente o Google anunciou o projeto Compute Engine (Google, 2013), com o mesmo objetivo.

Porém, apesar dos valores bastante baixos, da perspectiva de financiamento público de processamento científico, apenas contratar o processamento como serviço dessas empresas não é vantajoso. Um estudo patrocinado pelo DOE (Departamento de Energia dos Estados Unidos) aponta que o uso de nuvens publicas para simulações de computação intensiva pode ser mais caro do que a opção por adquirir e gerir os equipamentos. Em especial, um processamento nos centros de processamento do DOE são tipicamente de 2 a 13 vezes mais baratos do que se realizado em nuvens públicas (Yelick et al., 2011).

Alguns programas permitem a operação de nuvens computacionais, permitindo a criação de nuvens privadas. O projeto que se encontra mais maduro e é amplamente difundido é o OpenStack, desenvolvido com o apoio de diversos parceiros importantes, como a NASA e a Rackable. O código está sobre uma licença para software livre open source e é adotado na implementação de nuvens de todos os tamanhos, tanto acadêmicas como comerciais.

Outro projeto que visa desenvolver os componentes de software necessários é o OpenNebula, também com licença livre. Já o OpenHelix, financiado pelas agências de fomento europeias, visa estabelecer as bases para a utilização de nuvens para processamento científico.

\subsubsection{Armazenamento de dados}

$\mathrm{Na}$ terminologia recente, e utilizada para descrever as técnicas de armazenamento nas nuvens, é comum dividir os serviço de armazenamento em três classes:

- Objetos (object storage)

- Blocos (block device)

- Sistema de arquivos em rede (network file system)

O sistema de armazenamento de objetos prevê apenas operações de escrita e leitura sequencial, análogo ao que é oferecido pelo protocolo GridFTP. A vantagem desse mecanismo é uma ótima escalabilidade. Porém, não é possível alterar objetos, e só é possível processá-lo através do download.

Já dispositivos de bloco são recursos oferecidos dentro da nuvem acessíveis as máquinas virtuais como um dispositivo onde elas poderão criar sistemas de arquivos permanentes. Oferecem operações de seek e escrita aleatória. Porém, esse tipo de solução não tem boa escalabilidade, e muitas vezes fica restrita a anexação a uma máquina virtual por vez.

Por fim, sistemas de arquivos em rede podem ser ofertados para as máquinas virtuais, criando um mecanismo de acesso a arquivos usando o padrão POSIX ou similar entre diversas máquinas concorrentemente. Caso essa opção não esteja disponível diretamente, é possível criar esse sistema de arquivos em rede utilizando-se de dispositivos de bloco e iniciando máquinas virtuais com esse propósito na rede dedicada.

Algumas vezes também é mencionado o serviço de armazenamento de dado estruturados, DBaaS (Database as a Service). A oferta desse tipo de solução é crescente, mas não existe nenhuma padronização. Ela também não é essencial como oferta de serviços pois, utilizando apenas IaaS (máquinas virtuais + armazenamento em dispositivos de blocos), é possível atender essa demanda.

\subsection{Segurança}

A segurança de qualquer sistema computacional é um aspecto fundamental de sua arquitetura. Esse aspecto é ainda mais crítico quando os sistemas estão acessíveis através de redes publicas, como a Internet. 
A segurança de sistemas distribuídos envolve os seguintes aspectos:

- autenticação (identificação) de usuários e serviços

- autorização (acesso) seletiva aos recursos

- privacidade (confidencialidade)

- disponibilidade

A autenticação é o processo de identificar o usuário (ou serviço) e validar se essa identificação é autêntica. Sem essa funcionalidade corretamente garantida, um usuário malicioso pode se passar por um usuário legitimo. Da mesma forma para os servidores, sem essa garantia, um serviço malicioso pode ser passar pelo serviço autêntico e interceptar dados indevidamente.

A autorização estabelece quais operações determinado usuário (ou serviço) pode realizar. Ela permite uma delegação seletiva dessas operações, indispensável para sistema multiusuários com alguma complexidade. Por exemplo, um usuário pode ser autorizado a apagar os próprios arquivos, mas não os arquivos de outros usuários. Sem esse recurso, um usuário legítimo poderia acessar e apagar arquivos de outros usuários.

A privacidade (ou confidencialidade) estabelece os cenários onde as informações estão protegidas contra o acesso de terceiros. Por exemplo pode garantir que todas as transferências sejam realizadas utilizando uma conexão criptografada, o que impede (torna computacionalmente difícil) a inspeção por agentes externos. Dessa forma dados podem ser transferidos pela Internet com relativa segurança. A privacidade também envolve, além do dado em si, o metadado. Por exemplo, no contexto de federações científicas, geralmente é admitido que os dados de contabilidade são públicos. Assim, não se sabe qual o resultado de determinado processamento, mas se sabe, publicamente, quantas horas de processamento cada usuário utilizou. Em alguns cenários isso é aceitável, em outros, não.

A disponibilidade é a capacidade do sistema operar tanto sobre condições normais como em condições adversas. Na perspectiva da segurança, é a resiliência dos sistema é a capacidade de operar sobre a ação de agentes maliciosos controlando fatores externos. O exemplo mais comum são ataques de negação de serviço, onde um agente malicioso tenta tornar o sistema indisponível pala sobrecarga de requisições.

\subsubsection{Segurança em federações computacionais}

Em sistemas integrados sobre um único domínio administrativo, geralmente é empregada uma solução direta, que envolve:

1. Uma base de dados centralizada para autenticação e autorização

2. Criptografia na comunicação (SSL/TLS) e algumas vezes no armazenamento

3. Limitação da superfície de exposição ao limitar o acesso da rede interna a rede pública e firewalls que tentam impor limites de acesso

Essa base de dados guarda informações de registro (login, nome, email, telefone), informações de filiação (a que grupo ou departamento pertence), informações de papel/função (role). Exemplos dessas bases são NIS, LDAP ou Active Directory. Muitas vezes as informações de autenticação (senha, hash da senha, chave criptográfica) ficam armazenados nessas bases. Em outros, ficam em armazenados em sistemas específicos, como Kerberos e Radius.

O problema ganha complexidade ao se projetar sistemas distribuídos e pertencentes à diferentes domínios administrativos. Esses domínios distintos implicam que cada site é autônomo e possui uma equipe local de administração. O administrador local pode decidir, em última instancia, quem acessa cada recurso do seu sistema.

Nessas condições, uma base de dados centralizada não é adequada. É preciso utilizar algum método que permita distribuir as informações de autenticação e autorização entre os participantes da 
federação, permitindo que cada um gerencie os seus integrantes. Essa abordagem também propicia a integração local com outras bases de dados já existentes no contexto de uma universidade ou departamento.

\subsubsection{Infraestrutura de chave pública}

Criptografia de chave pública é uma técnica de criptografia que permite: 1) a comunicação segura através de canais inseguros; 2) a habilidade de verificar a origem da comunicação.

Uma Infraestrutura de Chaves Públicas - Public Key Infrastructure, em inglês (ICP) (PKI, em inglês) permite a criação, armazenamento, distribuição e revogação de certificados digitais que vinculam uma chave pública a um ente. Essa vinculação permite estabelecer a autoria da comunicação bem como a transmissão segura de informações.

\section{X.509}

X.509 é um padrão ITU-T para ICP. Entre outra coisas, define o formato dos certificados, listas de revogação, atributos e algoritmos aceitos. Nesse sistema, uma Autoridade Certificadora (AC) emite um certificado vinculando uma chave pública a um ente descrito no formato X.500, além de incluir outras identidades, como endereços de email ou Domain Name System (DNS).

Para seu funcionamento é necessário que os participantes tenham acesso, a priori ao certificado raiz da $\mathrm{AC}$.

Esse é um sistema amplamente utilizado, sendo fundamental para o funcionamento de todas as tecnologias de comunicação baseadas em Secure Sockets Layer (SSL) ou Transport Layer Security (TLS), como Hypertext Transfer Protocol over Secure Socket Layer (HTTPS). Por exemplo, todo o comércio eletrônico mundial se utiliza desse padrão. Porém ele é criticado por apresentar algumas falhas. Em especial, a sua complexidade, dificuldade de auditoria e a necessidade de confiar completamente em um conjunto crescente de AC. Nos últimos anos foram reportados alguns casos bastante significativos de AC que foram comprometidas e, como agravante, evitaram ao máximo informar que haviam sido comprometidas. Uma falha desse tipo compromete todo o sistema. Além disso, outro problema apresentado é o custo de emissão dos certificados.

\subsubsection{OpenID}

O OpenID é uma padrão aberto e um protocolo descentralizado que permite usuários serem autenticados em sites utilizando um gerenciamento de credenciais fornecidos por terceiros. Isso elimina a necessidade dos usuários criarem mecanismos de autenticação (por exemplo, senhas) em cada um dos serviços que utilizam.

Diversas organizações utilizam esse padrão (como provedores de autenticação ou aceitando esse método), entre elas Google, Microsoft, VeriSign, Yahoo!, IBM, PayPal. A versão atual é 2.0, finalizada em dezembro de 2007.

\subsubsection{OAuth}

O OAuth é um padrão aberto para autorização. Ele permite delegar de forma segura e controlada acesso a recursos do usuário em aplicações de terceiros. Isso é feito sem que o usuário tenha que fornecer a sua credencial (senha) para a aplicação requirindo acesso. Esse padrão foi elaborado para funcionar sobre Hypertext Transfer Protocol (HTTP). OAuth começou a ser desenvolvido em 2006, para responder uma necessidade de autorização criada pelo uso do OpenID.

A versão atual, 2.0, foi publicada como (Hardt, 2012, RFC6749) e (Jones e Hardt, 2012, RFC6750). Essa versão é uma evolução da primeira versão, com a qual é incompatível. Ela busca simplificar alguns mecanismos e suportar outros ambientes, como aplicações para celulares, estações de trabalho e aplicativos web. O Facebook utiliza exclusivamente a versão 2.0. O Google recomenda o uso desse mecanismo em todas as suas Application programming interface (API). A Microsoft anunciou suporte a essa especificação em 2011, ainda que de forma experimental. 
Um grande número de falhas de segurança foram identificadas em diversas implementações. Alguns especialistas em segurança declaram que o protocolo é intrinsecamente falho (Sun e Beznosov, 2012).

\subsubsection{SAML}

Security Assertion Markup Language (SAML) é um formato padronizado de dados (baseado em XML) para permitir a troca de informações de autenticação e autorização. Em especial, a troca de informações entre um provedor de identidade e um provedor de recursos.

Esse padrão foi criado pelo OASIS Security Services Technical Committee, em 2001. A última grande atualização foi feita em 2005, mas outras melhorias também foram realizadas através de extensões opcionais.

O requerimento principal do padrão é criar um mecanismo de single sign-on (SSO) para páginas da internet, onde um usuário só precisa se autenticar uma única vez para acessar uma coleção distinta de serviços. Nesse sentido funciona de forma similar ao OpenID.

A especificação SAML define três papeis: o agente principal (geralmente o usuário), o provedor de identidade (IdP) e o provedor de serviço (SP). Nos casos contemplados pela especificação, o usuário requisita um serviço a um SP. Em seguida, o SP requisita prova de identidade do IdP. Para emitir essa prova, o IdP pode exigir que o usuário se identifique, por exemplo com usuário e senha. Com na prova de identidade, o SP pode autorizar ou não acesso ao recurso requerido.

A versão 2.0, publicada em 2005, é amplamente utilizada em instituições governamentais, universidades e grandes corporações. 


\section{Capítulo 3}

\section{Panorama atual}

\subsection{Nuvens computacionais}

\subsubsection{Serviços}

A empresa Amazon ((Amazon, 2013)) foi a pioneira e ainda é a referência em prover serviço IaaS em nuvens computacionais. Inicialmente focada em virtualizar servidores de uso geral, a empresa anunciou em 2011 novas instâncias, mais adequadas ao processamento intensivo. Desde então diversas melhorias foram implementadas. Atualmente ela oferece máquinas virtuais com diversas configurações, como redes de baixa latência ou GPGPUs, por preços que variam de USD \$ 0,20 a USD $\$ 0,40$ por minuto de um servidor com 8 núcleos, e instâncias para uso oportunístico a partir de USD\$ 0,007. Na mesma linha, a Rackable também oferta produtos semelhantes e, recentemente o Google anunciou o projeto Compute Engine (Google, 2013), com o mesmo objetivo.

\subsubsection{Software}

Além da possibilidade de comprar o processamento dessas empresas provedoras, a tecnologia de nuvens permite criar uma estrutura própria de nuvem computacional, chamada de nuvem privada. Como explicado nos capítulos anteriores, a federação é composta pela integração dessas nuvens privadas.

Entre as soluções que permitem a criação dessas nuvens privadas, algumas são soluções baseadas em programas proprietários, como a VMware vSphere e Citrix CloudStack, e outras baseadas em código livre, como OpenStack, Eucaliptus e OpenNebula.

Pela natureza do licenciamento, custo e a possibilidade de customização, as plataformas em código aberto são a referência para implementar esse tipo de serviço, em especial no ambiente acadêmico. Dentre esses projetos, o que tem mais destaque é o OpenStack, desenvolvido com o apoio de diversos parceiros importantes, como a NASA e a Rackable. O código está sob uma licença para software livre open source e vem ganhando grande adoção na implementação de nuvens de todos os tamanhos, tanto acadêmicas como comerciais. Com um ciclo de desenvolvimento semestral, tem adicionado recursos e funcionalidade em uma velocidade impressionante.

Outro projeto que visa desenvolver os componentes de software necessários é o OpenNebula, também com licença livre. O projeto continua ativo mas recebe um número menor de atualizações.

\subsubsection{Padronização}

Nas nuvens computacionais, cada plataforma tem adotado a sua própria interface. Historicamente, a Amazon foi a pioneira ao prestar esse tipo de serviço, e sua interface (EC2) foi usada como referência para diversos outros serviços que a sucederam. Com o passar do tempo, as interfaces foram evoluindo e, sem um organismo normatizador, hoje são incompatíveis.

Como referência, algumas das interfaces são: Amazon EC2, Eucalyptus, OpenStack, OpenNebula, VMware vSphere, Google GCE, IBM SmartCloud e Microsoft Azure. 
A busca pela interoperabilidade fomentou algumas iniciativas, muitas vezes identificadas pelos termos InterCloud e MultiCloud. Em se tratando do problema mais amplo, relacionado a todo tipo de computação em nuvem (não apenas IaaS) e com escopo geral (não apenas ao meio acadêmico), vale destacar:

- Global Inter-Cloud Technology Forum (GICTF), Japão, 2009

- Primeiro IEEE International Workshop on Cloud Computing Interoperability and Services (InterCloud), França, 2010

- IEEE Cloud Computing - Standard for Intercloud Interoperability and Federation (SIIF), 2011

Porém, até agosto de 2014, nenhum grande resultado foi alcançado, ainda sendo um problema em aberto.

Voltado ao escopo mais restrito das plataformas de IaaS, existe a iniciativa Fedcloud Taskforce (Lezzi et al., 2013), do EGI. A proposta combina a utilização de outros protocolos já existentes (ou a serem especificados). Essa combinação parece seguir a escolha das tecnologias predominantes, combinado a um viés de adotar as tecnologias de grade computacionais nas lacunas, como no caso do registro, segurança e contabilidade. Sua composição está apresentada na figura 3.1.

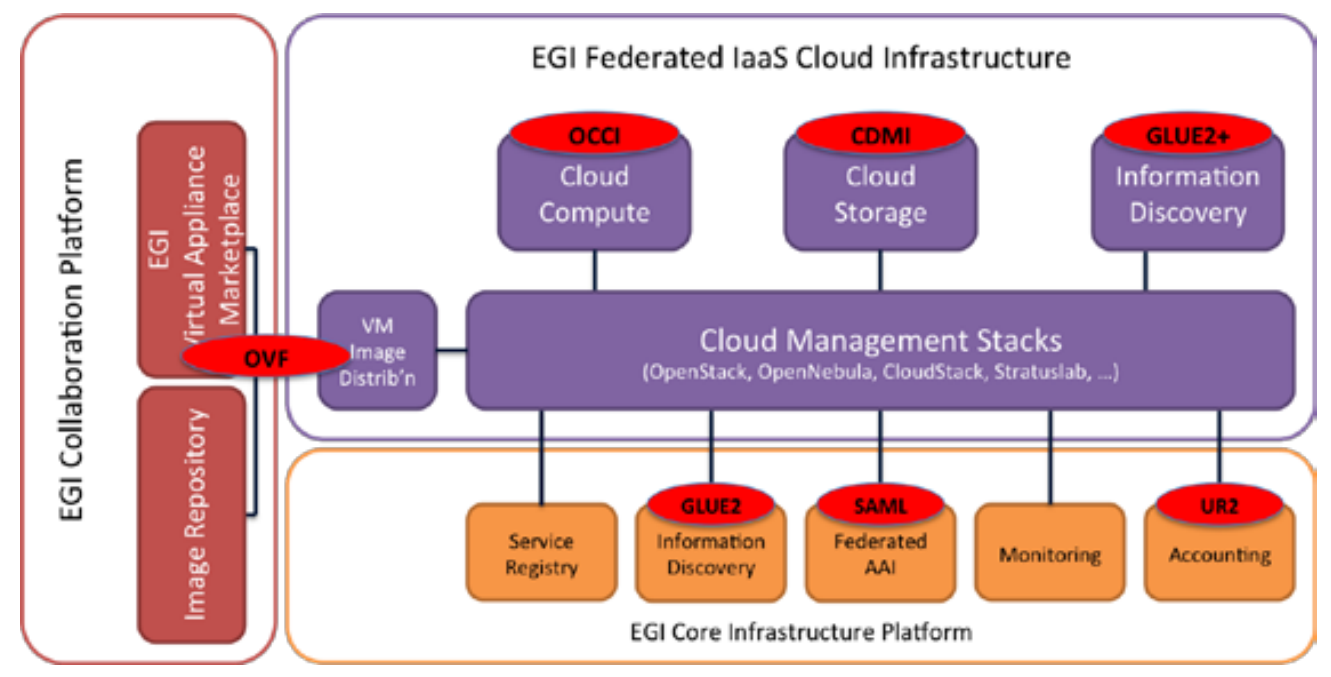

Figura 3.1: Arquitetura do Fedcloud. (fonte: EGI)

\section{Gerenciamento de execução}

O formato OVF(Open Virtualization Format), que especifica máquinas virtuais, é um padrão amplamente utilizado e foi aprovado pelo DMTF (Distributed Management Task Force).

Porém, além do formato da máquina virtual, é necessária a existência de um protocolo responsável pelo gerenciamento da execução (execution management) do processamento na nuvem. Como nessa plataforma a computação está encapsulada em máquinas virtuais, de forma concreta, esses protocolos gerenciam máquinas virtuais, com ações de provisionar, ligar e desligar (ou destruir) essas máquinas.

Existem protocolos introduzidos pelas plataformas, sendo o EC2, da Amazon, a referência pelo seu pioneirismo e o OpenStack Nova o mais adotado, pela popularidade do projeto. Além disso, existe uma tentativa de padronizar uma API, que está sendo elaborada no OCCI (Open Cloud Computing Interface), iniciativa estabelecida pelo OpenGridForum. Dessa iniciativa, já existe uma versão 1.1 dos protocolos definidos como core, que estabelece a API para as operações básicas de gerenciamento de máquinas virtuais. Porém diversos pontos ainda estão indefinidos, como os mecanismos de autenticação e autorização, limitando a sua aplicação. Algumas plataformas desenvolvidas 
com código livre, como OpenStack e OpenNebula, já aceitam, ainda que de forma limitada, essa interface. Nenhuma plataforma proprietária adotou a interface.

\section{Armazenamento de dados}

O principal protocolo para armazenamento de objetos nas nuvens é o S3, também introduzido pela Amazon, que ganhou importância pelo seu pioneirismo. Existem também outros protocolos, como por exemplo o OpenStack Swift. De forma análoga ao que ocorre com o processamento, existe a tentativa de padronização, sendo a mais destacada a CDMI (Cloud Data Management Interface) 1.0 .

Um detalhe importante a ser destacado é que, enquanto as grades contam com protocolos dedicados as transferências, as nuvens, que utilizam a comunicação através de HTTP, tentam adequar esse protocolo a tarefa, com diferentes graus de sucesso. Vale lembrar que o HTTP não foi desenvolvido para suportar o upload de grandes dados. Para mitigar essas limitações usa-se técnicas como chunking, que consiste em dividir o arquivo a ser enviado em partes menores, e fazer o envio em partes. Essa técnicas dependem de implementações no lado do servidor e do cliente, e poderiam ser simplificadas com a evolução do protocolo ou a utilização de um mecanismo específico.

\section{Autenticação e autorização}

As nuvens computacionais apresentam uma grande variedade de métodos de autenticação, que incluem (variando com a plataforma) LDAP, Kerberos, certificados X.509, OAuth, OpenID e Moonshot. Porém, não está claro um modelo para a criação de federações, tanto de autenticação como de autorização. E nesse crítico aspecto da infraestrutura, o esforço de padronização do OCCI não define um modelo. Um modelo deverá ser proposto no âmbito do OASIS (Organization for the Advancement of Structured Information Standards), que já tem um comitê nomeado para essa tarefa, composto por membros de diversas empresas, como a Microsoft, a RedHat e o Bank of America, mas nenhum resultado concreto foi produzido.

\section{Registro e descoberta}

Os protocolos de registro que estão sendo trabalhados para nuvens são o CIM (Common Information Model), na âmbito do DMTF e o GLUE v2, no Grid Open Forum.

O CIM é apoiado por empresas importantes, porém, talvez por sua abrangência, é bastante complexo, o que poderá limitar a sua potencial adoção.

Já o GLUEv2 é um protocolo das grades computacionais, que teria uma extensão, algumas vezes referenciado como Glue2+, para lidar com nuvens. Apesar da sua menção em alguns documentos do Open Grid Forum, não foi possível encontrar nenhum documento com a sua especificação e todos os links estavam quebrados, levando a entender que essa iniciativa não está mais ativa.

Existem alguns protocolos vinculados a plataformas específicas, como o OpenStack Keystone, mas não foram desenvolvidos para serem interoperáveis em federações.

Nas grades computacionais, esses dados são tipicamente armazenados em bancos de dados LDAP. Dessa forma o mecanismo de consulta utiliza o mesmo protocolo, LDAP. A utilização de um diretório LDAP, com um esquema adequado para os recursos das nuvens, parece uma escolha adequada. Porém, como os outros protocolos utilizam uma API REST com HTTP/JSON, exportar esses dados dessa forma provavelmente simplificará consideravelmente o desenvolvimento de aplicações.

\section{Monitoramento}

Não foram encontrados padrões para monitoramento para nuvens computacionais. Porém a integração à alguma plataforma de monitoramento já existente é relativamente trivial. Ainda assim, seria muito interessante definir uma estrutura de dados, possivelmente em JSON, para representar de forma padronizada os resultados dos testes. 


\section{Contabilidade}

O EGI Task Force Federated Clouds sugere a adoção de um UR+ (Cloud Usage Records), uma definição de registros XML bem completa capaz de descrever processo de grade e de nuvens. Uma vez definido, será necessário programar rotinas para extrair informações de utilização dos sistemas locais e exportá-las nesse novo padrão. No OpenStack o componente responsável por essa funcionalidade é o Ceilometer. É possível confeccionar um plugin capaz de exportar os dados no formato requerido.

\subsubsection{Bibliotecas e serviços de abstração}

Uma abordagem alternativa é prover uma API de compatibilidade externamente ao serviço da nuvem. Isso pode ser feito através de um serviço intermediário ou através de bibliotecas. DeltaCloud e libcloud.apache.org são exemplos dessas abordagens. Nessa abordagem, o site que provê o serviço precisa apenas expor a sua interface nativa. O usuário, ou algum serviço intermediário da federação, é responsável por utilizar esse protocolo nativo, e criar uma camada de abstração que facilite a sua programação.

O Deltacloud (Deltacloud, 2014) funciona como um serviço, que oferece uma API capaz de abstrair as diferenças entre as implementações de nuvens computacionais. O projeto foi iniciado em 2009 e é desenvolvido majoritariamente pela Red Hat e a fundação Apache como software livre. São oferecidas três API (no frontend): Uma própria do Deltacloud, CIMI (DMTF) e EC2 (Amazon).

O libcloud (libCloud, 2014) é uma biblioteca escrita em python que permite a interação com diversos serviços de computação em nuvem através de uma API unificada. Seu desenvolvimento começou em 2009, também está disponibilizada como código livre e é capaz de integrar mais de 30 provedores distintos, incluindo operações sobre computação, dados, balanceadores de carga e DNS. Bibliotecas similares também estão disponíveis para outras linguagens.

Uma vantagem adicional dessa abordagem é permitir, de forma imediata, a utilização de provedores comerciais em complemento aos sites disponíveis na federação.

\subsubsection{Análise das soluções existentes}

Como apresentado nas seções anteriores, a criação de federações de nuvens depende da definição de uma arquitetura envolvendo diversos componentes. A tabela 3.1 resume as especificações disponíveis (omitidas as especificações de soluções, como Amazon EC2, OpenStack,...).

\begin{tabular}{lll}
\hline Componente & Especificação & Órgão normatizador \\
\hline Máquina Virtual & OVF & DMTF \\
Computação & OCCI & OGF \\
Dados & CDMI & SNIA \\
Registro & CIMI & DMTF \\
& GLUEv2 + & OGF \\
Contabilidade & UR2 + & OGF \\
Autenticação e autorização & SAML & OASIS \\
& OAuth2 & IETF \\
\hline
\end{tabular}

Tabela 3.1: Especificações padronizadas para nuvens computacionais (omitidas as especificações de soluções)

Recapitulando de forma sucinta o que foi apresentado anteriormente, as especificações existentes são: a OCCI do Open Grid Forum para gerenciamento de execução, a CDMI do SNIA (Storage Networking Industry Association) para gerenciamento de dados, CIMI da Distributed Management Task Force (DMTF) e GLUEv2 do Open Grid Forum para registro, SAML para autenticação, como parte do OASIS, e UR2 para contabilidade, também no escopo do Open Grid Forum. ${ }^{1}$

\footnotetext{
${ }^{1} \mathrm{O}$ site (Standards, 2014) possuí uma extensa lista das especificações existentes, concluídas ou em desenvolvimento.
} 
A única formulação que pretende apresentar um espectro completo, similar ao apresentado nesse trabalho, é o Fedcloud Taskforce, do EGI. A proposta combina a utilização do OVF, OCCI, CDMI, GLUE2+, SAML, UR2 e um protocolo de monitoramento não especificado (figura 3.1).

Um problema comum com algumas dessas especificações, em especial com a CDMI e CIMI, é que são especificações amplas, criadas para diversos cenários com pouca possibilidades de uma implementação prática. Como exemplo, a especificação CDMI determina 45 grupos de funcionalidades (System-Wide CDMI Capabilities). O OpenStack Swift implementa parcialmente apenas uma. A implementação de referência da SNIA, duas. O sistema mais completo (CDMI-Z), implementa parcialmente apenas seis (Wikipedia, 2014). O próprio Fedcloud Taskforce usa esse argumento ao escolher o padrão GLUE2+ ao invés do CIMI (Globus, 2014).

Além de especificações distantes da realidade por sua complexidade, a padronização em muitos órgãos de normatização sofre com a lentidão em sua definição, comparado com o desenvolvimento tecnológico. A engenheira do Google Vidya Narayanan, que trabalhou por mais de 7 anos no IETF, argumenta que diversos interesses comerciais distintos e uma dificuldade em criar consenso levaramna a desistir de trabalhar na normatização (Narayanan, 2014). Ela ressalta que as normatizações são fundamentais, mas a forma como são feitas atualmente não acompanha o passo da inovação tecnológica. 


\section{Capítulo 4}

\section{Arquitetura proposta}

Como apresentado no capítulo anterior, o ecossistema da computação em nuvem é bastante amplo e diverso. Existem vários componentes disponíveis, mas que são incapazes de interoperar de uma forma ampla. Iniciativas para estabelecer as fundações para criação de federações de nuvens computacionais existem, mas apresentam limitações desencorajadoras.

Aqui é apresentada uma arquitetura alternativa, pensada para mitigar os problemas apontados. Essa proposta foi concebida tendo como base os requisitos que estão apresentados a seguir.

\subsection{Requisitos}

\subsubsection{Autonomia local}

Tendo como referência um dos conceitos fundamentais nas estruturas de grade, a autonomia local também exerce um papel central e norteia diversas escolhas.

Como destacado anteriormente, esse requisito tem uma dimensão técnica e outra política: tecnicamente implica que os administradores locais são os responsáveis pela administração dos recursos, reduzindo o trabalho de uma administração centralizada. Também implica que o acesso privilegiado de administrador está sempre restrito ao próprio site.

Politicamente, como nesse modelo de federação, o investimento em aquisição e administração continuam sob responsabilidade de cada instituição, é mais fácil justificar a disponibilização desses recursos tendo a garantia que a gerência final sob os mesmos continua sobre domínio da instituição. Muitas vezes esse movimento é acompanhado de uma garantia que os usuários locais (da instituição que adquiriu os recursos) terão prioridade no uso dos mesmo.

\subsubsection{Descentralização}

A ênfase na autonomia local favorece uma descentralização, de recursos e de administradores. Porém alguns serviços centrais são fundamentais para coordenar o funcionamento da federação, bem como são necessárias algumas decisões coordenadas.

Convém, para o fortalecimento dessa comunidade, adotar uma gestão executiva aberta e capaz de representar os diversos interesses, bem como uma política visando a transparência das decisões e dos dados.

Essa questão pode não parecer significativa, mas em retrospecto à algumas experiências interinstitucionais nas universidades brasileiras, adotar uma postura neutra, interinstitucional e aberta a novos membros pode ser o fator crítico para o sucesso ou fracasso do projeto.

\subsubsection{Resiliência}

Outro aspecto fundamental na definição de um sistema distribuído é sua tolerância a falhas. Isso pode ser entendido como a capacidade do sistema continuar operando mesmo quando um ou mais subsistemas apresentam defeito, seja ele acidental ou proposital. 
Em especial em um sistema de escala global, é importante considerar o funcionamento quando ocorre, por exemplo, a falha em um servidor, a perda de conectividade de um site ou até mesmo um evento catastrófico em uma determinada região.

Como o processamento e armazenamento são geograficamente distribuídos, a federação naturalmente apresenta uma maior resiliência quando comparado a sistemas operados por uma única instituição. Porém a arquitetura ainda depende, mesmo que em menor nível, de alguns serviços centrais. A esses é mandatório o funcionamento de modo redundante (HA, alta disponibilidade), existindo pelo menos duas instâncias em operação em localidades geográficas distintas.

\subsubsection{Manutenção}

O número de componentes envolvidos em uma estrutura de nuvem é bastante significativo, maior do que o presente nas grades computacionais. Como consequência dessa inerente complexidade, surge o desafio de integrar todos os componentes. Porém é fundamental que se entenda que esse desafio se estende além da integração inicial: cada componente também precisará ser mantido.

Essa manutenção ocorre pela correção de falhas, melhorias no sistema ou evolução dos protocolos. É extremamente interessante reutilizar componentes já existentes, desde que atendam aos requisitos, pois isso retira a responsabilidade da federação de mantê-los. A utilização de componentes baseados em software livre, com uma comunidade ativa, é muito interessante justamente por permitir a distribuição dessa responsabilidade por toda a comunidade que utiliza esse código. Além disso, permite algumas personalizações, necessárias em algumas situações.

Coloca-se como requisito minimizar o desenvolvimento a ser realizado dentro da federação, tendo em vista não só a sua rápida composição com as melhores soluções disponíveis atualmente, mas preocupando-se com a manutenção dessa estrutura, fundamental para a longevidade do projeto.

\subsubsection{Usabilidade}

Tendo mais uma vez o histórico das grades computacionais como referência, outro fator crítico é a usabilidade do sistema, em grande parte expressa na interface disponibilizada (API). Como explicado no capítulo 2, a tentativa de adotar a tecnologia mais sofisticada (no caso, java web services) custou ao Globus Toolkit anos de desenvolvimento que acabaram por ser abandonados em favor de uma interface mais simples.

Por isso, a interface dos diversos componentes deve buscar a simplicidade e a independência de plataforma ou framework.

Da mesma forma, a escolha de um modelo de segurança deve levar em consideração a facilidade de uso. Uma das maiores dificuldades dos usuário iniciantes nas grades computacionais são os mecanismos de segurança, que envolvem, por exemplo, a emissão de um certificado pessoal por uma AC.

Cabe também ressaltar que um dos objetivos é a democratização dos recursos computacionais. Isso implica, entre outras coisas, a utilização dos recursos por usuários com pouca intimidade com computação. Ou seja, o sistema deve ser o mais simples quanto possível, não só para programadores, mas também para pesquisadores de áreas completamente desconexas da computação.

\subsubsection{Segurança}

Estabelecer um modelo confiável de segurança é outro aspecto fundamental. E esse é um dos poucos, se não o único, componente que não poderá ser substituído sem a completa restruturação da federação.

A segurança, como também descrito no capítulo 2, deve fornecer um framework de autenticação, autorização, auditoria e privacidade sólido e confiável. Porém, com as tecnologias atuais, quanto mais exigimos desse mecanismo, pior a sua usabilidade. E isso conflita diretamente com o requisito anterior.

É preciso buscar um equilíbrio entre os dois requisitos. De forma concreta, é assumido que: 
- Os sistemas estarão continuamente conectados na internet. Desconexões são consideradas falhas;

- O modelo de segurança deve ser capaz de atender à dinamicidade das estruturas de nuvem, com criação e destruição programática de Máquina Virtual (MV)s;

- Toda a comunicação entre sites deve ser protegida, considerando que esses canais são inseguro por natureza;

- As informações em custódia dos sites estarão acessíveis aos administradores do mesmo. A adoção de criptografia de dados é opcional e sua implementação a critério do grupo de pesquisa;

- Todas as informações de utilização dos recursos serão públicas;

- O gerenciamento de usuários deve ser descentralizada e requerer o mínimo de intervenção manual.

\subsubsection{Flexibilidade}

O último requisito é a flexibilidade da arquitetura. Em outras palavras, a capacidade de evoluir e se adaptar a evolução das tecnologias e componentes envolvidos. Novamente tendo as grades computacionais como referência, definir interfaces muito rígidas impede a evolução tecnológica. Essas interfaces rígidas por vezes foram excessivamente limitantes, estimulando o desenvolvimento de protocolos alternativos, quebrando a padronização e adicionando uma significativa complexidade ao sistemas.

Nos sistemas de computação em nuvem esse aspecto é ainda mais sensível porque a tecnologia ainda está em franco desenvolvimento e os programas e serviços estão evoluindo com uma velocidade impressionante. Acreditar que temos hoje uma visão clara de qual o melhor mecanismo para ofertar essa plataforma nos próximos cinco anos é uma ilusão. O que se dirá de algumas décadas.

A título de exemplo, a possibilidade de criar redes complexas, com sub-redes e roteamento, entre as máquinas virtuais é uma funcionalidade desenvolvida nos últimos meses no OpenStack. Essa funcionalidade tem um potencial muito interessante. Porém, essa possibilidade não está prevista no protocolo Open Cloud Computing Interface (OCCI). Em outro exemplo, está em desenvolvimento um novo componente (Trove) que disponibiliza bancos de dados como serviço (DB as a service). Esse componente permite utilização de bases de dados tipo $S Q L$ e NoSQL. Esse componente também não está previsto em nenhuma especificação. Na verdade, nem a API interna ao OpenStack foi estabelecida.

\subsection{Organização e agentes}

$\mathrm{Na}$ figura 4.1 é apresentada uma estrutura geral de todos os componentes da federação. Eles estão agrupados em quatro classes: grupos de pesquisa, grupos de recursos, operação central e conselho gestor. A seguir são explicadas cada um desses agrupamentos.

\subsubsection{Grupos de pesquisa}

Os grupos de pesquisa representam os usuários da federação e as infraestruturas associadas para auxiliá-los a consumir os recursos disponíveis. Nas grade, são as VO. Os usuários podem ser agrupados por afinidade de pesquisa, e não necessariamente por instituição. Além dos usuários normais, é previsto o papel de um coordenador, responsável por incluir e excluir membros. Opcionalmente pode existir um grupo de suporte local, que pode auxiliar usuários desse grupo, e administrar os recursos existentes para acessar a federação.

Entre esses recursos estão, por exemplo, servidores de acesso com os programas necessários já configurados. No caso do grupo optar por usar um servidor próprio de autenticação e autorização, esse também precisará ser mantido. 

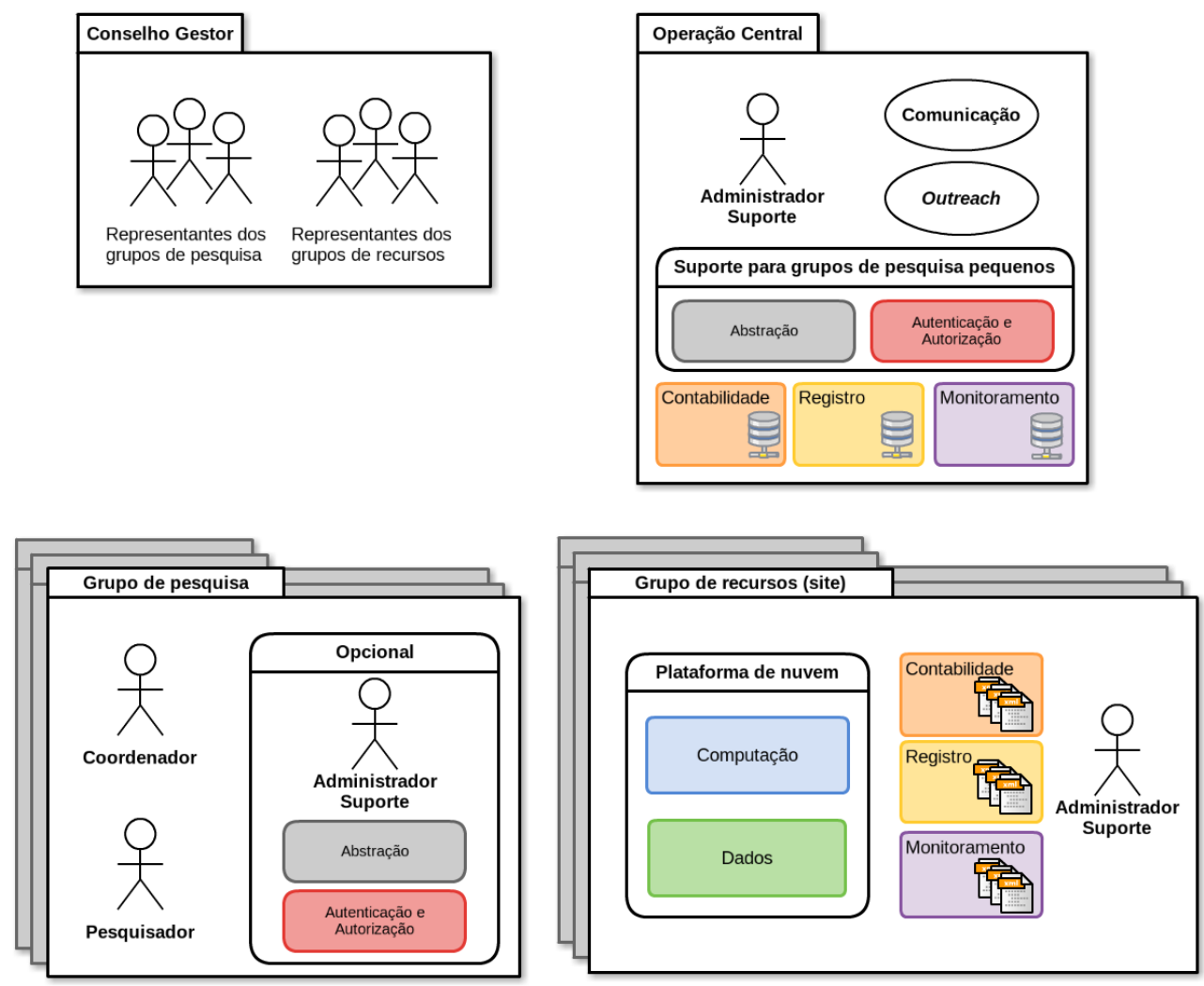

Figura 4.1: Estrutura da federação

De forma resumida:

- Pessoas

- Usuário

- Coordenador

- Suporte técnico local (opcional)

- Serviços (todos opcionais)

- Abstração

- Autenticação e autorização

- demais ferramentas de envio (submissão)

\subsubsection{Grupos de recursos}

Representam os recursos computacionais (e os recursos humanos necessários para o seu funcionamento). São os provedores de recursos, como processamento ou armazenamento. Na nomenclatura das grades, e algumas vezes empregada aqui como sinônimo, são os sites. Como tais, devem ser agrupados por domínio administrativo e proximidade geográfica.

Além do recurso em si, representado pelo GRL (por exemplo, OpenStack), inclui a coleção de serviços necessários para o funcionamento da federação. Esses serviços serão melhor detalhados na seção 4.3 (em especial nos itens 4.3.3 e 4.3.5), mas incluem serviços de contabilidade e monitoramento, entre outros.

Essa composição também inclui os administradores locais dos recursos, responsáveis por sua manutenção e suporte.

De forma resumida: 
- Pessoas

- Administradores locais

- Serviços

- Computação (GRL)

- Dados (GRL)

- Registro

- Contabilidade

- Monitoramento

\subsubsection{Operação central}

A operação central é um grupo único dentro da federação e tem a função de coordenar as atividades dentro da federação e facilitar a comunicação entre os diversos grupos. Os recursos computacionais sob a sua alçada são necessários para consolidar as informações dispersas entre os diversos sites, compilando uma bases de dados com:

- Registro

- Contabilidade

- Monitoramento

Para facilitar a utilização dos recursos por grupos de pesquisa com poucos recursos, deve prover para estes:

- Abstração

- Autenticação e autorização

No que tange a comunicação e desenvolvimento da federação, esse grupo precisará manter documentações técnicas, sistemas de ticket, listas de email, suporte avançado aos usuários, suporte avançado aos administradores e quaisquer programas desenvolvidos no escopo da federação.

Por fim, atividade de divulgação e outreach também estão a cargo desse grupo.

\subsubsection{Conselho gestor}

A função do conselho gestor é administrar o grupo de operações centrais e definir as políticas das federação. É um agrupamento estritamente administrativo e composto pelos stakeholders da federação, representando tanto os donos dos recursos computacionais como os seus usuários.

\subsection{Componentes e protocolos}

Uma vez definido os papeis dentro da federação, é possível detalhar os componentes e protocolos que permitem, na prática, a utilização dos recursos.

Tendo como base as tecnologias que são o estado da arte, tenta-se aqui fazer uma composição de forma a atender da melhor forma os requisitos estabelecidos. Entre as escolhas de projeto, duas delas merecem uma atenção especial. 


\subsubsection{Interface fluida}

A primeira decisão divergente do apresentado em outros projetos, como FedCloud e o OCCI, é a opção por não estabelecer um protocolo único de abstração de recursos locais.

O que se propõe aqui é a criação de federações de nuvens computacionais através de uma escolha fluida (dinâmica) de protocolos para a interface dos sites. Para cada funcionalidade pode ser definido um conjunto de protocolos aceitáveis. Essa escolha poderá ser revista periodicamente, acrescentando novos protocolos e removendo protocolos obsoletos. Sua utilização poderá ser feita utilizando bibliotecas e serviços de conversão para criar uma camada de abstração. Isso possibilita a escolha de protocolos desenvolvidos por produtos e não apenas entidades de normatização, baseado em sua popularidade em sistemas reais.

A única definição que precisa ser rígida é um sistema de autenticação e autorização distribuído capaz de prover uma infraestrutura unificada para os demais serviços.

\subsubsection{Simplicidade ao invés de funcionalidade}

Conforme apresentado na seção 3.1.5, o histórico de formatos e protocolos que optam por oferecer um conjunto muito amplo de funcionalidades, tende a torná-los complexos e de difícil implementação. Por isso optou-se por privilegiar a simplicidade e facilidade de implementação.

Essa opção levou a adotar, quando possível, interfaces baseadas em: HTTP (transporte), Representational State Transfer (ReST) (lógica da interface) e JavaScript Object Notation (JSON) (formato de dados). Essas tecnologias estão amplamente utilizadas.

O protocolo HTTP foi escolhido por ser suportado em todos os componentes pesquisados. Existem algumas limitações, em especial na transferência (especificamente o upload) de grandes quantidades de dados utilizando esse mecanismo. Outros protocolos são reconhecidamente mais eficientes, mas exigem a implementação de uma camada completamente distinta de transporte. Isso limitaria o seu uso em navegadores de internet (considerando o uso sem plugins ou websockets). Como mostra a história do Globus OnLine, o problema de entregar os dados ao usuário final (last mile) pode ser tão ou mais importante que a transferência otimizada entre dois sites. De qualquer forma existem formas de mitigar essas limitações.

A lógica ReST permite simplificar de forma significativa o desenvolvimento dos serviços, principalmente no que tange a escalabilidade. Alternativas como Simple Object Access Protocol (SOAP) e Common Object Request Broker Architecture (CORBA) oferecem mais recursos, mas implicam em uma complexidade adicional (ou a vinculação a framework específicos).

O formato de dados preferencial é o JSON, adotado pela sua simplicidade e popularidade. Alguns dos componentes já bem estabelecidos utilizam XML, como no caso do SAML. Nesse caso, mantêm-se o formato existente. Quando for possível, é melhor oferecer ambos os formatos.

\subsubsection{Segurança, autenticação e autorização}

Estabelecer um framework robusto de segurança é o passo inicial ao estabelecer a arquitetura da federação. E como descrito anteriormente, é o componente mais difícil de ser alterado, uma vez que é utilizado por todos os demais componentes.

Considerando que, caso bem sucedida, uma federação como a descrita aqui será composta por uma quantidade bastante considerável de recursos, ela possivelmente se tornará um alvo importante de ataques virtuais. Por isso, a escolha desse mecanismo deve estar a par desse desafio e prover mecanismos de contingenciamento.

Nas grades, foi amplamente adotado o GSI, baseado em uma estrutura ICP com certificados um padrão para criação de sistemas de ICP (X.509). Essa foi uma opção adequada à época, permitindo a operação em offline, e considerada até hoje como bastante segura. Porém o custo dessa estrutura é grande. Hoje é mantida uma estrutura de CA dedicada aos sistemas de grade, todos os serviços precisam de resolução reversa de DNS corretamente configurada e é bastante trabalhosa a adição de novos membros. 
$\mathrm{Na}$ ausência de alternativas bem estabelecidas, a comunicação com os servidores ainda depende da estrutura de ICP, usado para estabelecer conexões seguras SSL ou TLS. Porém, no que diz respeito à autenticação e autorização dos usuários, é cada vez mais empregado o conceito de token, emitido sobre demanda.

Nesse modelo, o primeiro passo é o usuário se autenticar com suas credenciais, recebendo em troca um token. Esse token pode ter validade e escopo limitados. Nesse modelo é possível delegar acesso a terceiros e também revogar trivialmente o acesso em caso de uma falha de segurança. Como vantagem adicional, não exige uma complexa estrutura de ICP.

Baseado nesse modelo, e adequadas tanto para a autenticação como para a autorização, as duas soluções mais consistentes são o SAML e o OAuth, como apresentados no capítulo 2. Ambos protocolos tem funcionalidades similares. O padrão SAML é consideravelmente mais complexo, mas o seu uso é mais difundido e, pela sua longevidade, mais testado. O OAuth é um protocolo mais simples, e muito mais imaturo.

Como em termos de funcionalidades os dois padrões são equivalentes, uma escolha mais conservadora e amplamente testada é mais adequada como solução de segurança. Por essa razão, esse trabalho recomenda o uso do SAML.

O protocolo SAML é implementado por uma variedade de programas. Entre as soluções mais utilizadas para disponibilizar um provedor de identidade Identity Provider (IdP) estão o Shibboleth (Morgan et al., 2004) e o OpenAM (Thangasamy, 2011).

\subsubsection{Computação, dados e abstração}

Como explicado anteriormente, essa arquitetura tem como diferencial a exposição das interfaces nativas dos recursos, fazendo uso de serviços e bibliotecas de abstração (apresentadas no item 3.1.4). A escolha dos protocolos nativos aceitos na federação deve ser dinâmica.

Como escolha inicial, define-se: Amazon EC2, OpenStack Nova e OCCI para o gerenciamento da computação. Amazon S3 para o armazenamento de dados em objetos. Para a abstração, sugere-se a utilização da biblioteca libcloud e do serviço deltacloud, quando conveniente.

Dessa forma, a responsabilidade do site se limita a expor os seus recursos através de uma das interfaces aceitas para computação (EC2, OpenStack Nova 2, OCCI) e dados (EC2), utilizando SAML (além de exportar informações dos recursos e sua utilização, como explicado a seguir).

A responsabilidade dos grupos de pesquisa se limita a criar o seu próprio domínio de autenticação e autorização, utilizando SAML, denominado provedor de identidade. Opcionalmente ele pode delegar esse papel ao grupo de operações centrais.

\subsubsection{Registro, monitoramento e contabilidade}

Os serviços de registro, monitoramento e contabilidade dependem de três elementos:

- formato dos registros

- rotinas de conversão

- base de dados de consolidação e consulta

Como descrito no capítulo 3, existem algumas iniciativas buscando a definição dos formatos, como GLUE2+ e CIM para registro e UR + para contabilidade, mas todas as iniciativas ainda estão incipientes. Uma desvantagem do GLUE2+ é a utilização de Lightweight Directory Access Protocol (LDAP), ao invés de HTTP e JSON. Porém, como é a extensão de um protocolo existente, é recomendado por se acreditar que é o caminho mais produtivo de desenvolvimento.

Da mesma forma, o protocolo UR + deve ser considerado para a contabilidade, por se tratar da extensão de um protocolo bem definido e amplamente utilizado. Caso seja possível investir no desenvolvimento desses componentes, a utilização de uma API REST com HTTP/JSON, simplificaria o desenvolvimento de aplicações. Da mesma forma, optar por banco de dados não relacional 
( $n o S Q L)$ na modelagem dos registros pode resolver um possível problema de desempenho, uma vez que ele se manifesta de forma análoga nas grades computacionais.

\subsection{Casos de uso}

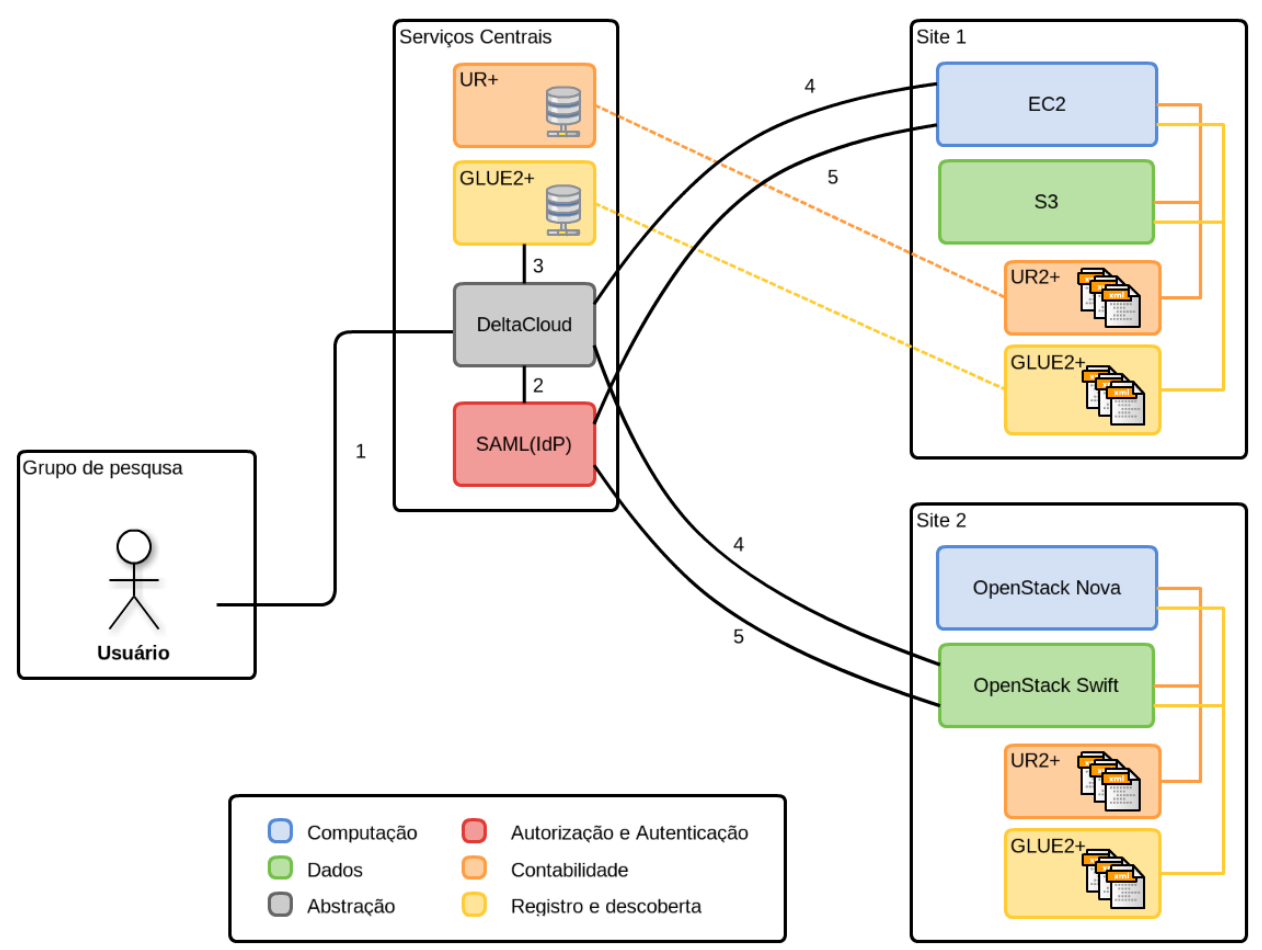

Figura 4.2: Caso de uso 1: Grupo de pesquisa pequeno ou usuário iniciante

A seguir são apresentados dois casos de uso. O primeiro, apresentado na figura 4.2 exemplifica o caso onde um pesquisador que participa de um grupo de pesquisa pequeno, que opta por utilizar os serviços de abstração e autenticação oferecidos pela federação (serviços centrais). Note que nesse caso, os recursos dispendidos pelo grupo de pesquisa são mínimos, favorecendo a entrada de novos grupos. Nesse exemplo o usuário está usando um serviço de abstração, o deltaCloud.

As etapas representadas são: (1) envio da requisição para o servidor de abstração; (2) autenticação e autorização desse usuário no serviço de abstração; (3) seleção do provedor de recurso; (4) solicitação, em nome do usuário, do recurso ao GRL do grupo de recursos escolhido; (5) autenticação e autorização desse usuário no serviço requisitado; 


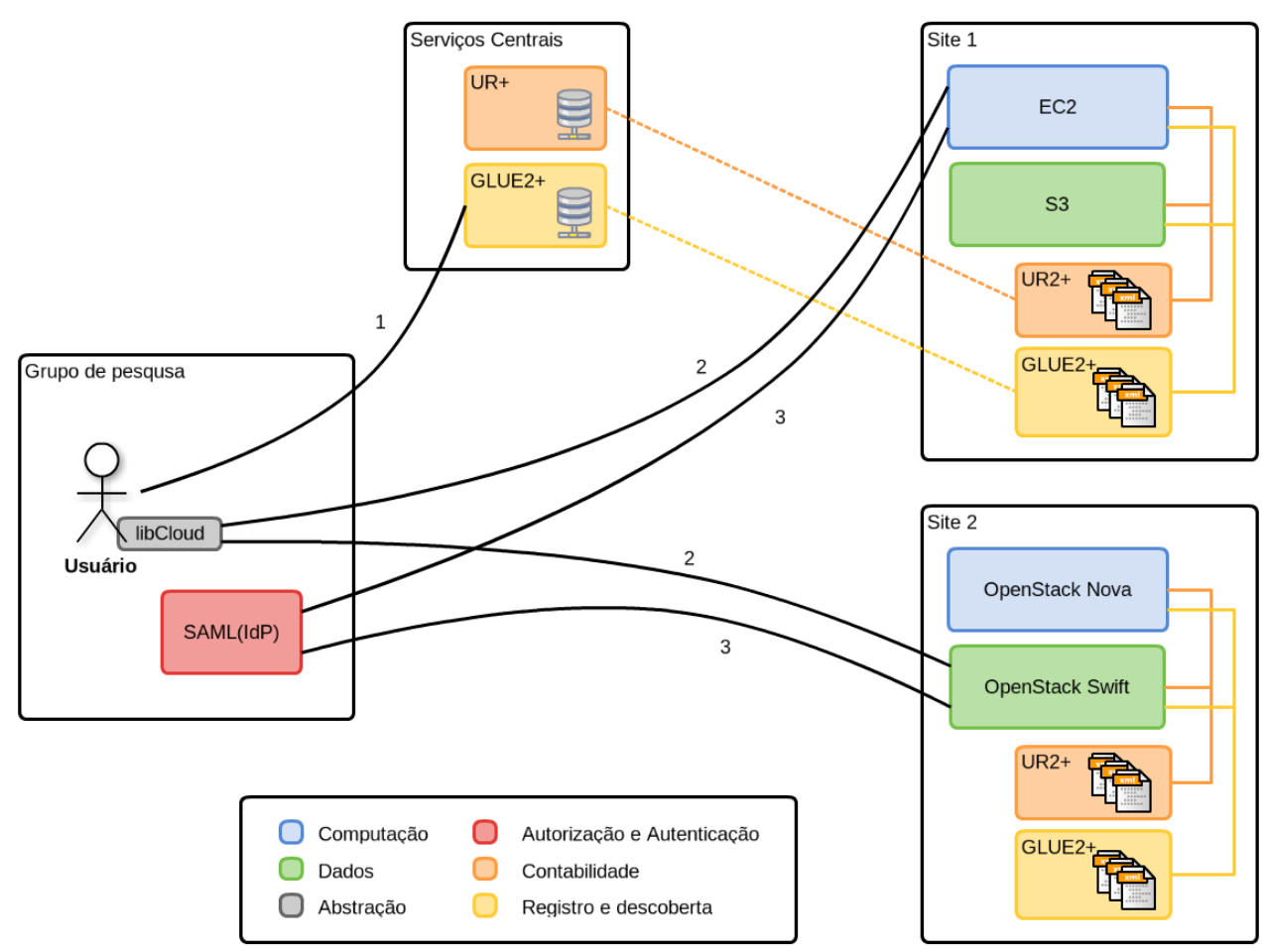

Figura 4.3: Caso de uso 2: Grupo de pesquisa de grande porte

No segundo exemplo, figura 4.3, está retratado o potencial de utilização por um grupo maior de pesquisa, que opta por gerenciar internamente a autenticação e autorização. Esse grupo poderia também criar um serviço de abstração, como no exemplo anterior. Nesse caso porém está representada a utilização de uma biblioteca de abstração, a libCloud.

As etapas representadas são: (1) seleção do provedor de recurso; (2) envio da requisição através de uma biblioteca de abstração local; (3) autenticação e autorização desse usuário no serviço requisitado; 


\section{Capítulo 5}

\section{Implementação e resultados}

\subsection{Implementação de teste}

A arquitetura apresentada no capítulo anterior fornece uma solução teórica capaz de atender à todos os requisitos levantados. Mas qual a viabilidade prática dessa solução? E o quão distante ela está de uma aplicação em ambiente real de produção?

Visando responder a essas questões, optou-se por realizar um teste de conceito, simulando o funcionamento de alguns dos componentes que estariam presentes em uma federação de nuvens computacionais. Com esse teste buscou-se, além de validar a arquitetura proposta, entender a quantidade de modificações e adaptações que serão necessárias para colocar um ambiente completo em produção.

Pela quantidade limitada de recursos, o problema foi reduzido a sua essência:

- modelo de autenticação e autorização

- mecanismo de abstração

Alguns objetivos nortearam a escolha desses itens. Em primeiro lugar, eles representam o mínimo para estabelecer uma estrutura de federação de nuvens computacionais, ao passo que também são suficientes para a criação de uma estrutura produtiva. Os demais serviços, como contabilidade, monitoramento e registro podem ser vistos como secundários. No caso do registro, como é necessário para a seleção de recursos, pode ser substituído por informações estáticas dos conjuntos de recursos potencialmente disponíveis.

A segunda razão foi para testar a principal característica que diferencia essa proposta de trabalhos similares: o uso de uma interface de abstração externa ao provedor de recursos. Caso não seja prático operar com esse modelo, todo trabalho perde a sua fundamentação.

Por fim, testar de forma prática a interoperabilidade dos principais componentes, utilizando as plataformas mais populares, e que provavelmente são as que serão utilizadas para a criação das nuvens fornece um importante indicador de o quanto de desenvolvimento será necessário para a consolidação dessa proposta. Por exemplo, dado o estado de maturidade de um dos recursos necessários em um dos componentes a 10 meses atrás, esse teste não seria possível.

Foi desenhado o seguinte cenário:

1. Um grupo de pesquisa conta com um servidor de autenticação e autorização SAML;

2. Um usuário, pertencente a esse grupo de pesquisa, está registrado nesse servidor;

3. Um grupo de recursos (site) de outra instituição disponibiliza recursos de computação e dados.

Objetivo: O usuário deve ser capaz de acessar os recursos do site através de um sistema de abstração e sem possuir qualquer cadastro prévio nesse site.

Esse cenário está representado na figura 5.1. 


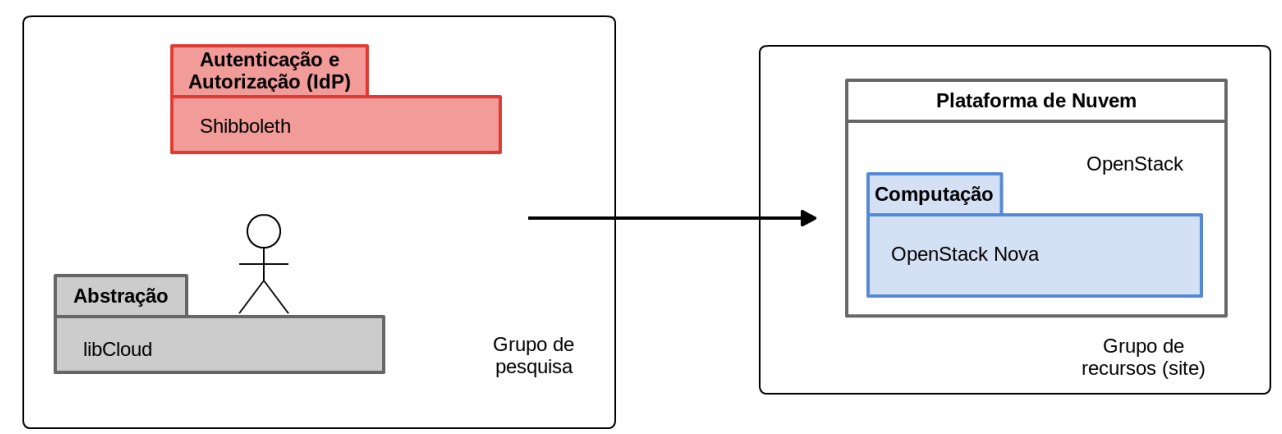

Figura 5.1: Teste de conceito

\subsubsection{Ambiente}

Para o servidor de autenticação foi utilizado o programa Shibboleth Identity Provider, 2.4.0, distribuído com licença de código livre, capaz de prover autenticações e autorizações SAML 2.0. Essa plataforma foi adotada pelo número de funcionalidade, nível de maturidade e adoção na comunidade acadêmica internacional. Para o teste, não foi necessária nenhuma modificação no servidor de identidade.

O mecanismo utilizado para autenticar o usuário junto ao seu provedor de identidade está fora do escopo da federação e, por tanto, desse trabalho. O mecanismo a ser adotado varia com a infraestrutura já existente na instituição, podendo utilizar senha, certificados X.509, token Kerberos, entre outros. Por simplicidade, e sem perder a generalidade, adotou-se autenticação com usuário e senha em uma base de dados local.

Para a plataforma de recursos foi utilizado o OpenStack, versão Icehouse, também sobre licença livre. Essa plataforma é referência na implementação de nuvens computacionais privadas, razão da escolha. É importante destacar que, em uma situação concreta, a nuvem a ser compartilhada pode já existir como recurso aos usuários locais da instituição, independente da filiação à federação. Nesse caso, o modelo aqui proposto terá que se adequar a essa plataforma. Novamente a escolha do OpenStack se justifica, ao ser a plataforma mais provável também nesse cenário.

Para a sua utilização foi necessária uma configuração especial para permitir a autenticação através de um mecanismo externo. Essa configuração só foi possível devido a melhorias no código introduzidas na versão Icehouse. Em outras palavras, esse teste não seria possível antes do lançamento dessa versão. Como esse teste foi planejado antes do lançamento da mesma, se acompanhou o desenvolvimento da plataforma por todo ciclo, entre a versão anterior (Havana) e essa. Estão planejadas mais modificações para tonar mais fácil a utilização desse programa em ambientes de autenticação distribuída, como federações.

Para a abstração foi utilizada a biblioteca libcloud, 0.14.1, para python, também disponível como código livre. Nesse componente poderia-se utilizar qualquer biblioteca ou serviço de abstração. Pela familiaridade com a linguagem utilizada, optou-se por esse. Utilizando a biblioteca foi desenvolvido um pequeno programa de teste, capaz de fazer a requisição de um token utilizando a autenticação SAML, e, em seguida, instanciando uma máquina virtual. Essa rotina está no Anexo A.

\subsubsection{Etapas}

A figura 5.2 representa as etapas envolvidas no processo de requisição do recurso:

1. O usuário requisita ao provedor do recurso um token temporário;

2. O provedor responde com um redirecionamento, acrescido de um payload que o usuário deve validar junto ao provedor de identidade; 


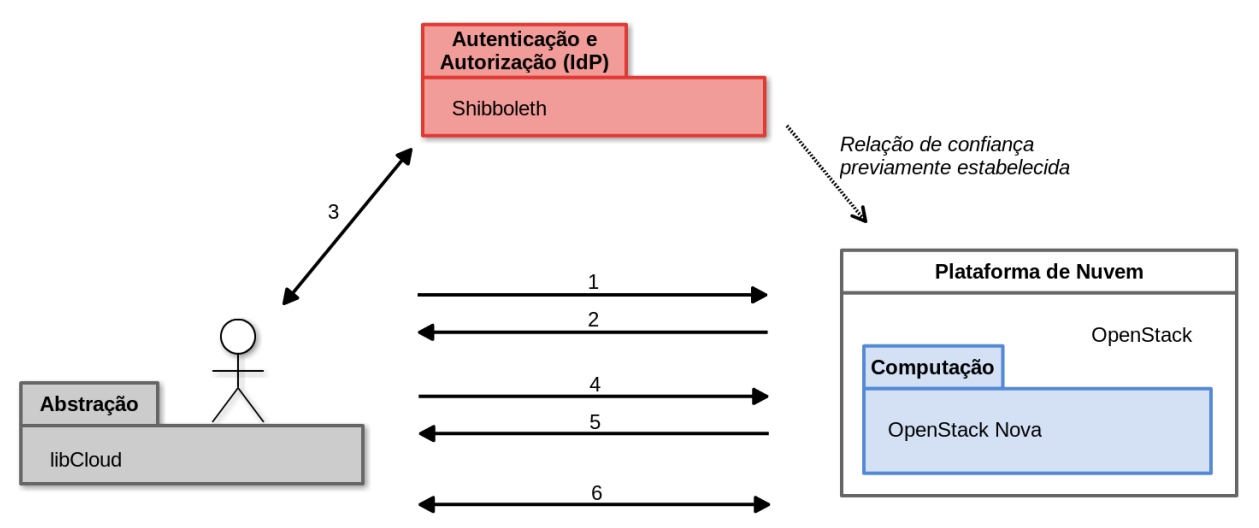

Figura 5.2: Etapas do teste de conceito

3. O usuário solicita essa validação ao provedor de identidade, tendo a sua identificação validada por algum mecanismo. Esse mecanismo pode variar, mas tipicamente é usado senha ou um certificado X.509;

4. Em seguida o usuário retorna ao provedor de recurso, com a prova de autenticação;

5. Em troca, o provedor fornece um token definitivo;

6. De posse desse token definitivo, o usuário pode finalmente requisitar o recurso, como em uma requisição regular a uma nuvem privada local;

\subsection{Resultados}

Toda a dificuldade para realizar esse teste se concentrou na tarefa de estabelecer a relação de confiança entre o provedor de identidade e o provedor de recursos utilizando SAML. Contribuíram para essa dificuldade a falta de experiência com esse protocolo e sua complexidade.

Uma vez superada essa etapa, o restante no teste de conceito funcionou muito bem. A biblioteca de abstração é muito bem construída e, como esperado, simplifica muito a utilização dos recursos.

Para a realização desse teste foi necessária a configuração de um ambiente apropriado. Isso exigiu, por exemplo, a criação de um servidor com resolução reversa de nomes corretamente configurada, além da emissão de certificados X.509. Os certificados podem ser emitidos por uma AC de testes, mas ainda assim, pode ser uma tarefa desafiadora.

Estabelecer a relação de confiança entre o provedor de identidade e o provedor de recursos também não é uma tarefa particularmente fácil, o que justifica a fama do protocolo SAML de ser difícil de configurar. Porém, essa é uma tarefa que só precisa ser realizada uma única vez para cada relação entre provedor de identidade e provedor de recurso, e será realizada apenas por administradores de recursos. Como o usuário final não se envolverá nesse processo, não chega a prejudicar a usabilidade da arquitetura.

Por outro lado, a utilização da biblioteca se mostrou extremamente simples. Essa biblioteca é bem documentada e apresenta uma gama impressionante de recursos. Ela será uma solução adequada mesmo quando forem utilizados workflows complexos.

A API para autenticação em federações do OpenStack poderia ser mais simples, mas sua utilização foi bastante direta, uma vez que esse recurso foi corretamente disponibilizado.

Para medir o sucesso do teste, pode-se avaliá-lo com base nos requisitos da arquitetura:

autonomia local Bem sucedido. A administração dos recursos foi mantida no escopo local, sendo apenas necessário estabelecer a relação de confiança entre os provedores de recurso e identidade, uma operação bastante familiar a organizações que já utilizam SAML. Ao utilizar a 
interface local da plataforma de nuvem, também se manteve a autonomia local na escolha do seu gerenciador de recurso.

descentralização Previsto na arquitetura, mas não testado. Como esse teste foi simplificado para a existência de um único componente de cada tipo, essa característica não foi exercitada. Porém, a inclusão de outros provedores é trivial.

resiliência Previsto na arquitetura, mas não testado. Como explicado no item anterior, esse teste foi simplificado para a existência de um único componente de cada tipo.

manutenção Bem sucedido. Não foi necessária nenhuma alteração à nenhum dos programas, o que significa que as versões disponibilizadas (e mantidas) pelos desenvolvedores originais poderão ser usadas.

usabilidade Bem sucedido. A utilização da biblioteca de abstração apresentou uma API simples, e ainda assim muito poderosa.

segurança Bem sucedido. O nível de segurança é equivalente ao de plataformas que já utilizam SAML, presente em diversas organizações e tida como suficiente.

flexibilidade Bem sucedido. Ao utilizar a interface nativa do gerenciador de recursos local, está garantida a independência do protocolo de comunicação para a evolução das tecnologias de nuvem.

Em função desses parâmetros, pode-se concluir que, ainda que limitado em seu escopo, o teste mostra que essa arquitetura é uma solução viável. Além disso, os componentes disponíveis hoje já permitem a integração de recursos respeitando todos os requisitos aqui levantados. Na prática, essa arquitetura apresenta uma solução para a criação de federações de nuvens computacionais. 


\section{Capítulo 6}

\section{Conclusão}

A forma como são realizadas as pesquisas científicas tem mudado significativamente em diversas áreas do conhecimento. Em grande parte, essa mudança se deve a oferta de ferramentas computacionais.

Novas técnicas de virtualização estão provocando profundas mudanças nas infraestruturas computacionais. As nuvens computacionais estão mudando a forma como recursos computacionais são disponibilizados. Esse novo modelo está se popularizando rapidamente, inclusive no ambiente acadêmico. Diversas universidades e institutos de pesquisa estão investindo ou planejam investir na aquisição de recursos desse tipo.

A possibilidade de compartilhar recursos computacionais entre os centros de pesquisa traz benefícios a todos, ao aumentar a quantidade de recursos disponíveis e maximizar a sua taxa de utilização. Quando se considera que, no Brasil, grande parte dos recursos financeiros investidos na compra desses equipamentos é pública, a boa gestão desses recursos é uma responsabilidade social.

Federações de grades computacionais são exemplos bem sucedidos de compartilhamento de recursos entre diferentes instituições. Ao longo desse trabalho foram analisados os componentes dessas estruturas para propor uma arquitetura equivalente aplicada a nuvens computacionais.

Como foi mostrado pela ampla análise das soluções existentes, o ecossistema envolvendo nuvens computacionais é muito rico e dinâmico. Existem diversos componentes, mas nenhuma solução efetiva para o problema da interoperabilidade e compartilhamento de recursos.

Pela combinação de alguns componentes e protocolos já existentes, esse trabalho propõe uma arquitetura capaz de atender diversos requisitos: autonomia local, descentralização, resiliência, manutenção, usabilidade, segurança e flexibilidade.

Outras iniciativas propuseram arquiteturas semelhantes, com destaque para a FedCloud. Porém uma característica chave diferencia a proposta apresentada nesse trabalho: A exposição das interfaces nativas nos GRL e a utilização de serviços e bibliotecas de abstração.

Essa possibilidade permite a criação imediata das federações, utilizando grande parte da tecnologia já disponível. Outra vantagem determinante é permitir que a tecnologia dos componentes continuem evoluindo.

Para validar essa abordagem, foi desenvolvida uma prova de conceito. Apesar do seu escopo restrito, o resultado foi muito animador. Esse teste mostrou que essa abordagem não só é factível como apresenta grandes vantagens. Sua aplicação foi bastante simples, tanto da perspectiva dos administradores de recursos, como, principalmente, dos usuários.

Dessa forma, esse trabalho apresenta uma arquitetura completa e flexível para a criação de federações de nuvens computacionais e prova, ainda que em um escopo que não engloba todos os componentes de uma federação totalmente desenvolvida, que é possível criar essas estruturas imediatamente. Diante dos promissores resultados, acredita-se que um passo foi dado tendo em vista o ideal de otimizar o uso e democratizar o acesso de pesquisadores a recursos computacionais científicos. 


\subsection{Trabalhos futuros}

O passo imediato é estender a prova de conceito para utilizar outros mecanismos de abstração, como o deltacloud. Também é importante aprofundar os casos de uso, criando novos testes para avaliar as funcionalidades disponíveis através da abstração. Outro caminho é testar essa abstração em outras plataformas, como o OpenNebula.

Mas apenas com o resultado já obtido é possível contatar alguns interessados nessa tecnologia e tentar aplicá-la em uma escala maior. É importante lembrar que o aspecto mais importante em uma federação computacional não é a tecnologia ou os recursos, mas a comunidade de pessoas que ela aglutina.

A iniciativa de estabelecer uma cooperação será um problema mais político do que técnico. Para facilitar essa mudança de paradigma, podem ser estabelecidos compartilhamentos de recursos bilaterais, iniciando a comunidade com apenas dois parceiros, e deixando a criação dos componentes necessários a uma federação multilateral para uma segunda etapa.

Para o completo desenvolvimento da estrutura, será necessário o desenvolvimento de alguns componentes. A figura 6.1 apresenta os componentes prontos e os que ainda precisam ser desenvolvidos. Dessa forma, o desenvolvimento se restringe à:
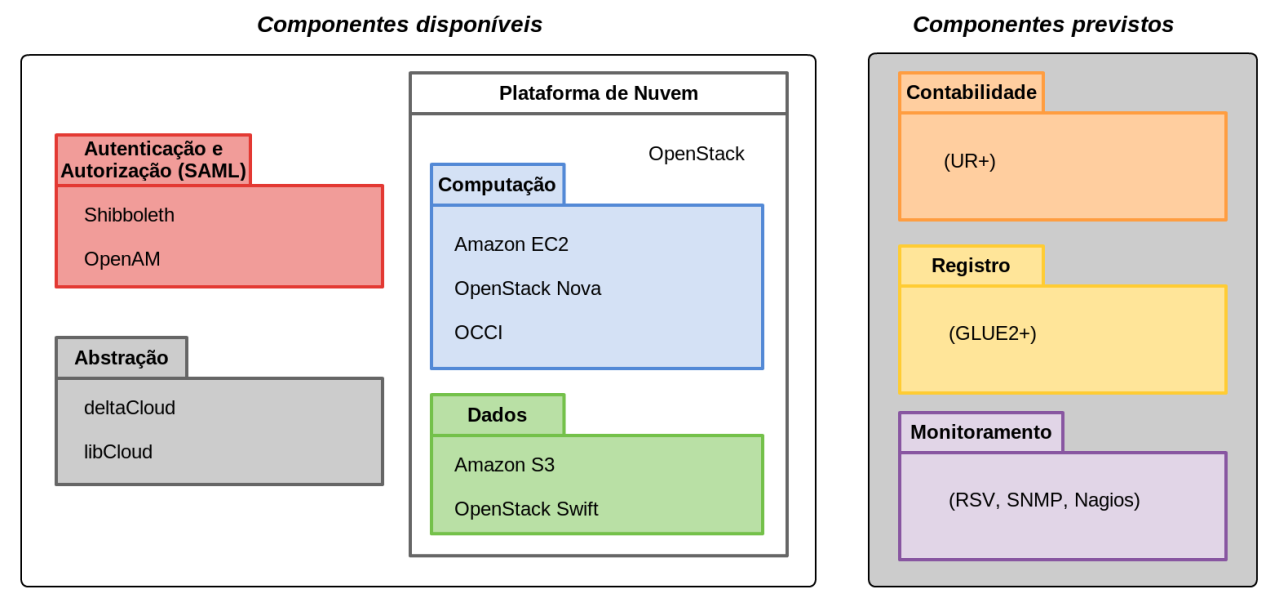

Figura 6.1: Disponibilidade dos componentes

- Base de dados de registro (coleta, tratamento e exibição)

- Base de dados de contabilidade (coleta, tratamento e exibição)

- Sistema de monitoramento

- e para cada GRL suportado:

- rotina de conversão dos dados de contabilidade

- rotinas de monitoramento e disponibilidade

Nenhum desses componentes é critico, o que significa que uma federação pode começar a operar sem eles. Com o fortalecimento dessa comunidade, essas lacunas podem ser preenchidas gradativamente, bem como a oferta de documentação e suporte.

Um problema correlacionado, ainda em aberto, é a criação de mecanismos eficientes para priorização de recursos em nuvens computacionais. Uma política simples de priorização baseado em filiação e preempção destrutiva atende aos requisitos básicos de uma colaboração. Mas mecanismos mais sofisticados, incluindo reserva e suspensão não destrutiva, podem otimizar substancialmente o aproveitamento dos recursos. 
Por fim, algumas das reflexões apontadas nesse trabalho poderão ser usadas para evoluir as tecnologias das grades. Qualquer mudança nessas estruturas enfrenta uma resistência maior, uma vez que já são estruturas bem estabelecidas. Mas alguns aspectos, como o conceito de utilizar sistemas de abstração fora dos sites e expor a interface nativa, ou ainda a utilização de modelos de segurança mais dinâmicos, podem trazer benefícios significativos para essas estruturas. 


\section{Apêndice A}

\section{Programa de teste}

Programa desenvolvido para a execução do teste de conceito, em python.

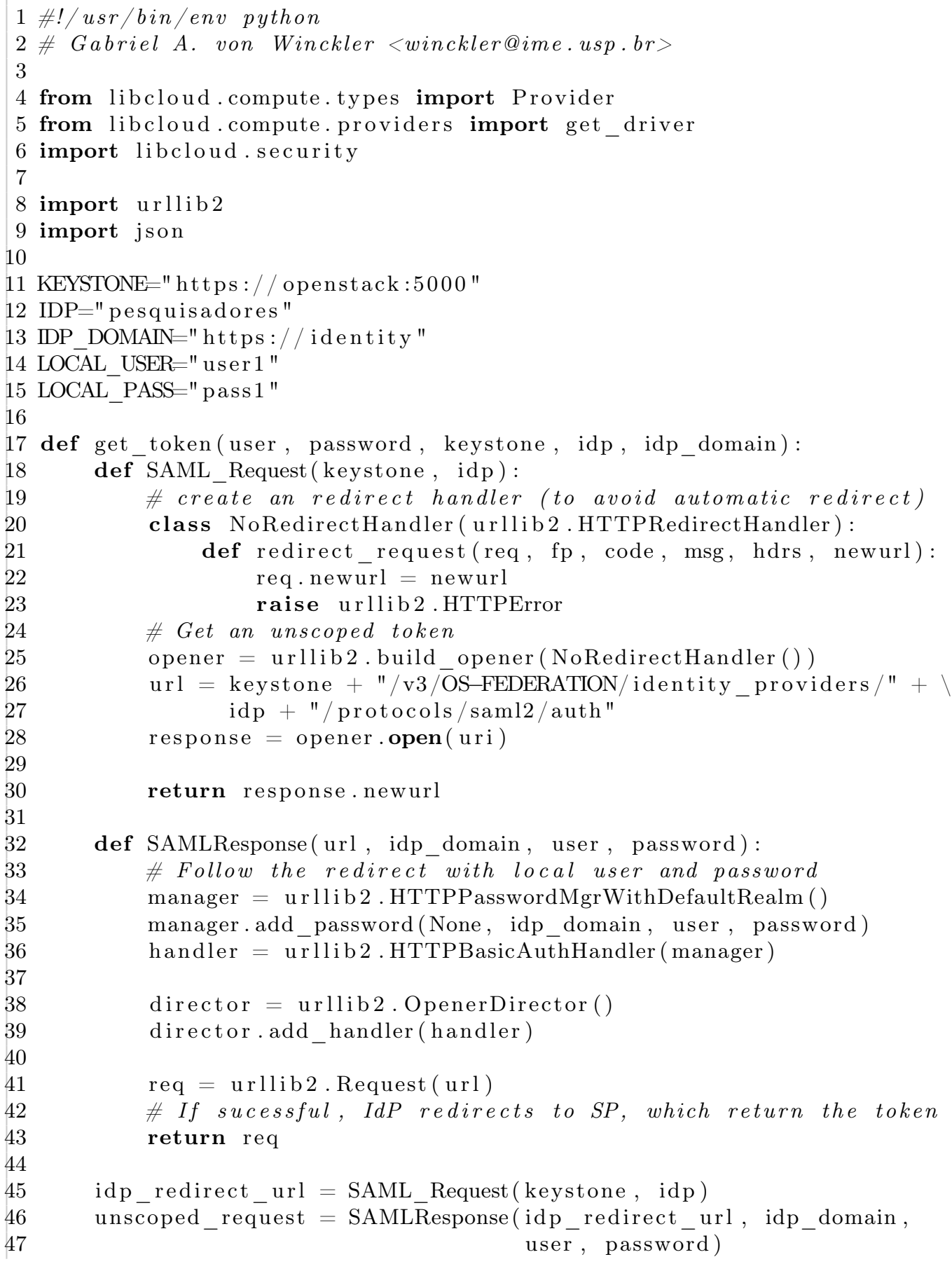




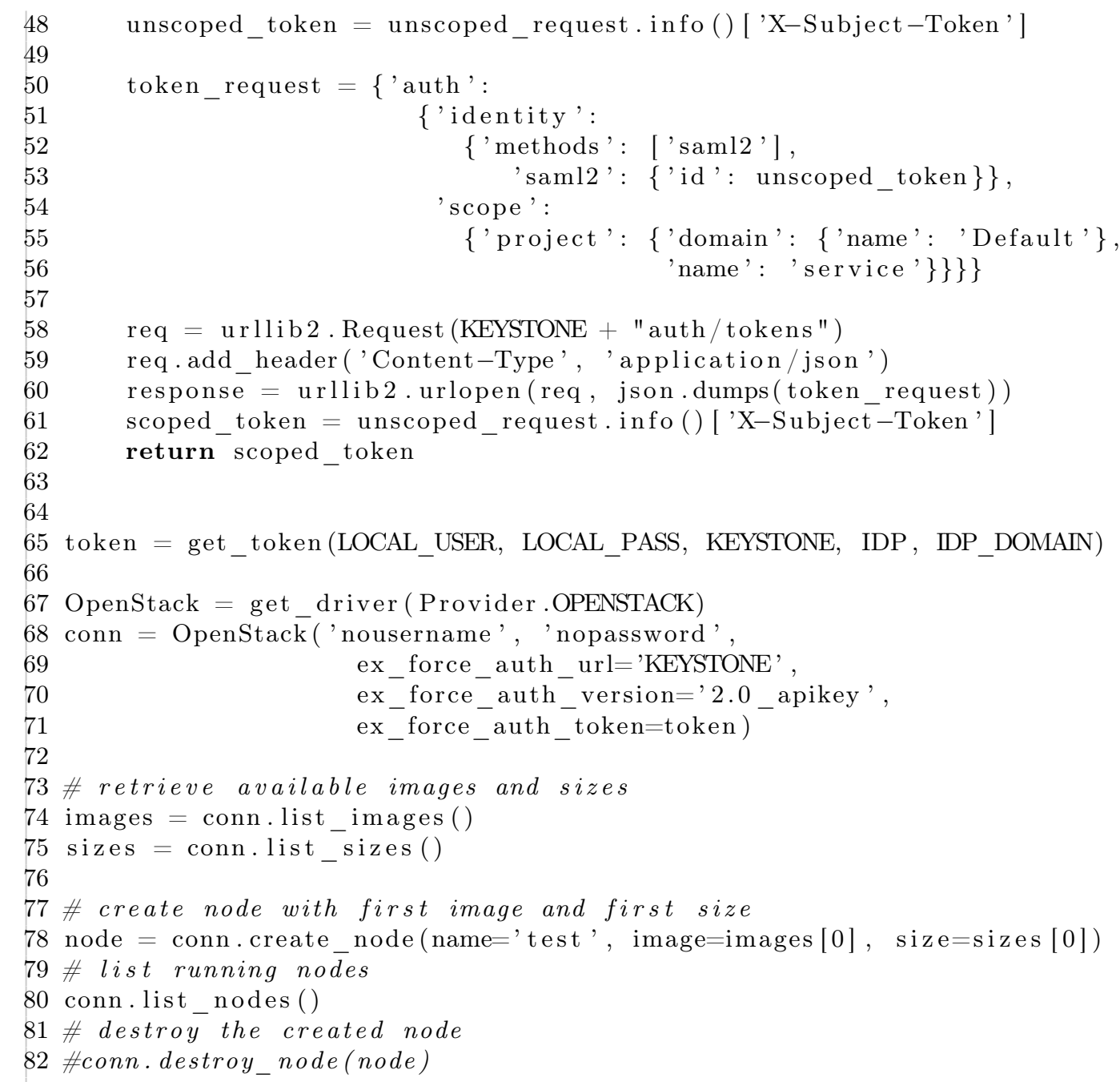




\section{Referências Bibliográficas}

Amazon (2013) Amazon. Amazon EC2, 2013. URL http://aws.amazon.com/ec2/. Acessado em 29/04/2013. Citado na pág. 13, 18

Andreetto et al. (2006) P Andreetto, SA Borgia, A Dorigo, A Gianelle, M Marzolla, M Mordacchini, M Sgaravatto, F Dvorák, D Kouril, A Krenek et al. Cream: a simple, grid-accessible, job management system for local computational resources. CHEP 2006, Mumbay, India. Citado na pág. 7

Armbrust et al. (2009) Michael Armbrust, Anthony D Joseph, Randy H Katz e David A Patterson. Above the Clouds : A Berkeley View of Cloud Computing. Science, 53(UCB/EECS-2009-28): 07-013. ISSN 00010782. doi: 10.1145/1721654.1721672. Citado na pág. 1, 13

Armbrust et al. (2010) Michael Armbrust, Rean Griffith, Anthony D Joseph, Randy Katz, Andy Konwinski, Gunho Lee, David Patterson e Ariel Rabkin. A view of cloud computing. Communications of the .... doi: 10.1145/1721654.1721672. Citado na pág. 13

Canal (2011) Philippe Canal. Gratia: New challenges in grid accounting. Journal of Physics: Conference Series, 331(6):062028. URL http://stacks.iop.org/1742-6596/331/i=6/a=062028. Citado na pág. 11

Cirne et al. (2006) Walfredo Cirne, Francisco Brasileiro, Nazareno Andrade, Lauro B Costa, Alisson Andrade, Reynaldo Novaes e Miranda Mowbray. Labs of the world, unite!!! Journal of Grid Computing, 4(3):225-246. Citado na pág. 2

De et al. (2012) K. De, A. Klimentov, S. Panitkin, M. Titov, A. Vaniachine, T. Wenaus, D. Yu e G. Zaruba. Poster: PanDA: Next Generation Workload Management and Analysis System for Big Data. Em 2012 SC Companion: High Performance Computing, Networking Storage and Analysis, páginas 1523-1523. IEEE. ISBN 978-0-7695-4956-9. doi: 10.1109/SC.Companion.2012.302. Citado na pág. 8

Deltacloud (2014) Deltacloud. Deltacloud, 2014. URL https://deltacloud.apache.org/. Acessado em 14/06/2014. Citado na pág. 21

Foster et al. (2002) I. Foster, C. Kesselman, J.M. Nick e S. Tuecke. Grid services for distributed system integration. Computer, 35(6):37-46. ISSN 0018-9162. doi: 10.1109/MC.2002.1009167. Citado na pág. 6

Foster (2003) Ian Foster. Grid Computing: Making the Global Infrastructure a Reality. ISBN 0470853190. URL http://books.google.com/books?hl=pt-BR\&lr=\&id=b4LWXLRBRLsC\& pgis $=1$. Citado na pág. 6

Foster (2011) Ian Foster. Globus Online: Accelerating and democratizing science through cloudbased services. Internet Computing, IEEE. Citado na pág. 1, 9

Foster et al. (2008) Ian Foster, Yong Zhao, Ioan Raicu e Shiyong Lu. Cloud Computing and Grid Computing 360-Degree Compared. 2008 Grid Computing Environments Workshop, páginas 1-10. doi: 10.1109/GCE.2008.4738445. Citado na pág. 2 
Globus (2014) Globus. GLUE2 Design, 2014. URL http://confluence.globus.org/display/IIS/ GLUE2+Design. Acessado em 19/07/2014. Citado na pág. 22

Google (2013) Google. Google Compute Engine, 2013. URL https://cloud.google.com/products/ compute-engine. Acessado em 29/04/2013. Citado na pág. 14, 18

Grid (2014) Open Science Grid. BOSCO, 2014. URL http://bosco.opensciencegrid.org/. Acessado em 14/06/2014. Citado na pág. 8

Hardt (2012) D. Hardt. The OAuth 2.0 Authorization Framework. RFC 6749 (Proposed Standard), Outubro 2012. URL http://www.ietf.org/rfc/rfc6749.txt. Citado na pág. 16

Jones e Hardt (2012) M. Jones e D. Hardt. The OAuth 2.0 Authorization Framework: Bearer Token Usage. RFC 6750 (Proposed Standard), Outubro 2012. URL http://www.ietf.org/rfc/ rfc6750.txt. Citado na pág. 16

Leake (2012) Elizabeth Leake. Globus and Grid: Blazing Trails for Future Discovery, 2012. URL http://www.hpcinthecloud.com/hpccloud/2012-09-13/globus_and_grid:_blazing_trails_ for_future_discovery.html. Citado na pág. 5

Lezzi et al. (2013) Daniele Lezzi, Francesc Lordan, Roger Rafanell e Rosa M Badia. Execution of scientific workflows on federated multi-cloud infrastructures. Em Euro-Par Workshops, páginas 136-145. Citado na pág. 19

libCloud (2014) libCloud. Python library for interacting with many of the popular cloud service providers using a unified API., 2014. URL https://libcloud.apache.org/. Acessado em 14/06/2014. Citado na pág. 21

Morgan et al. (2004) RL Morgan, Scott Cantor, Steven Carmody, Walter Hoehn e Ken Klingenstein. Federated security: The shibboleth approach. Educause Quarterly, 27(4):12-17. Citado na pág. 29

Narayanan (2014) Vidya Narayanan. Why I quit writing internet standards, 2014. URL http: //gigaom.com/2014/04/12/why-i-quit-writing-internet-standards/. Acessado em 19/07/2014. Citado na pág. 22

Pordes et al. (2010) R Pordes, the Open Science Grid Executive Board e J Weichel. Analysis of the current use, benefit, and value of the Open Science Grid. Journal of Physics: Conference Series, 219(6):062024. ISSN 1742-6596. doi: 10.1088/1742-6596/219/6/062024. Citado na pág. 6

Sfiligoi (2008) I Sfiligoi. glideinWMS - a generic pilot-based workload management system. Journal of Physics: Conference Series, 119(6):062044. ISSN 1742-6596. doi: 10.1088/1742-6596/119/ 6/062044. Citado na pág. 8

Simons (2012) Josh Simons. ISC Cloud 2012 BOFs: Applications/Software, Reference Architectures and Data Transfer, 2012. URL http://www.hpcinthecloud.com/hpccloud/2012-10-02/isc cloud_2012_bofs:_applications_software_reference_architectures_and_data_transfer.html. Citado na pág. 2

Standards (2014) Cloud Standards. Cloud standards list, 2014. URL http://cloud-standards.org. Acessado em 19/07/2014. Citado na pág. 21

Sun e Beznosov (2012) San-Tsai Sun e Konstantin Beznosov. The devil is in the (implementation) details: an empirical analysis of oauth sso systems. Em Proceedings of the 2012 ACM conference on Computer and communications security, páginas 378-390. ACM. Citado na pág. 17

Thangasamy (2011) Indira Thangasamy. OpenAM. Packt Publishing Ltd. Citado na pág. 29 
Tuecke et al. (2004) S. Tuecke, V. Welch, D. Engert, L. Pearlman e M. Thompson. Internet X.509 Public Key Infrastructure (PKI) Proxy Certificate Profile. RFC 3820 (Proposed Standard), Junho 2004. URL http://www.ietf.org/rfc/rfc3820.txt. Citado na pág. 9

Wikipedia (2014) Wikipedia. Comparison of CDMI server implementations, 2014. URL http://en.wikipedia.org/wiki/Comparison_of_CDMI_server_implementations. Acessado em 19/07/2014. Citado na pág. 22

Yelick et al. (2011) Katherine Yelick, Susan Coghlan, Brent Draney, Lavanya Ramakrishnan, Adam Scovel, Iwona Sakrejda, Anping Liu, Scott Campbell, Piotr T Zbiegiel, Tina Declerck, Paul Rich, Nicholas J Wright, Linda Winkler, Nathan M Mitchell, Michael A Guantonio, Levi J Lester, Gabriel A West, David Skinner, Wei Lu e Eric R Pershey. The Magellan Report on Cloud Computing for Science The Magellan Report on Cloud Computing for Science. Relatório técnico. Citado na pág. 14

Zeilenga (2006) K. Zeilenga. Lightweight Directory Access Protocol (LDAP): Technical Specification Road Map. RFC 4510 (Proposed Standard), Junho 2006. URL http://www.ietf.org/rfc/ rfc4510.txt. Citado na pág. 10 